Buehler et al. 1

\title{
EGR1 transcriptional control of human cytomegalovirus latency
}

\section{Jason Buehler ${ }^{1}$, Ethan Carpenter ${ }^{1,2}$, Sebastian Zeltzer ${ }^{1}$, Suzu Igarashi ${ }^{1}$, Michael Rak ${ }^{1}$,} lliyana Mikell ${ }^{3}$, Jay A. Nelson ${ }^{3}$, and Felicia Goodrum ${ }^{1,4}$

${ }^{1}$ BIO5 Institute, University of Arizona, Tucson, AZ 85721

${ }^{2}$ Current Address for Ethan Carpenter: Neuroscience Program, Macalester College, St. Paul, MN 55105

${ }^{3}$ Vaccine and Gene Therapy Institute, Oregon Health \& Science University, Beaverton, Oregon, 97006, USA

${ }^{4}$ Department of Immunobiology, University of Arizona, Tucson, AZ 85721

Running title: EGR1 regulates UL138 for CMV latency

*Corresponding Author:

Felicia D. Goodrum, PhD

Department of Immunobiology

BIO5 Institute

University of Arizona

Tucson AZ 85721

(520) 626-7468

fgoodrum@email.arizona.edu 
Buehler et al. 2

\section{ABSTRACT}

Sustained phosphotinositide3-kinase (PI3K) signaling is critical to the maintenance of herpesvirus latency. We have previously shown that the beta-herpesvirus, human cytomegalovirus (CMV), regulates epidermal growth factor receptor (EGFR), upstream of PI3K, to control states of latency and reactivation. Inhibition of EGFR signaling enhances CMV reactivation from latency and increases viral replication, but the mechanisms by which EGFR impacts replication and latency is not known. We demonstrate that HCMV downregulates MEK/ERK and AKT phosphorylation, but not STAT3 or PLCY for productive replication. Similarly, inhibition of either MEK/ERK or PI3K/AKT, but not STAT or PLC $\gamma$, pathways increases viral reactivation from latently infected $\mathrm{CD} 34^{+}$hematopoietic progenitor cells (HPCs), defining a role for these pathways in latency. We hypothesized that CMV modulation of EGFR signaling might impact viral transcription. Indeed, EGF-stimulation increased expression of the UL138 latency gene, but not immediate early or early viral genes, suggesting that EGFR signaling promotes latent gene expression. The early growth response-1 (EGR1) transcription factor is induced downstream of EGFR signaling through both PI3K/AKT and MEK/ERK pathways. EGR1 expression is important for the maintenance of HPC stemness and its downregulation drives HPC differentiation and mobilization. We demonstrate that EGR1 binds upstream of UL138 and is sufficient to promote UL138 expression. Further, disruption of EGR1 binding 52 upstream of UL138 prevented CMV from establishing a latent infection in CD $34^{+}$HPCs. Our

53 results indicate a model whereby UL138 modulation of EGFR signaling feeds back to promote

54 UL138 expression and suppression of replication to establish or maintain viral quiescence. 
Buehler et al. 3

57 CMV regulates EGFR signaling to balance states of viral latency and replication. CMV blocks downstream PI3K/AKT and MEK/ERK signaling pathways through down-regulation of EGFR at the plasma membrane. PI3K/AKT and MEK/ERK signaling increases expression of the EGR1 transcription factor that is necessary for the maintenance of stem cell stemness. A decrease in EGR1 expression promotes HPC mobilization to the periphery and differentiation, a known stimulus for CMV reactivation. We identified functional EGR1 binding sites upstream of the UL138 gene and EGR-1 binding stimulates UL138 expression. Additionally, down-regulation of EGR1 by CMV miR-US22 decreases UL138 expression emphasizing the importance of this transcription factor in expression of this latency gene. Lastly, we demonstrate that a CMV mutant virus lacking an upstream EGR1 binding site is unable to establish latency in CD34 ${ }^{+}$ HPCs. This study defines one mechanism by which EGFR signaling impacts viral gene expression to promote CMV latency.

\section{INTRODUCTION}

71 The mechanisms by which herpesviruses persist through the establishment of a quiescent

72 infection, known as latency, and reactivate for continued transmission are incompletely defined.

73 It is known that herpesviruses sense and respond to changes in the host cell signaling, such as

74 that associated with stress and differentiation, to modulate the decisions to maintain latency or

75 to reactivate. However, the molecular underpinnings of how these cellular signals induce

76 changes in chromatin and viral gene expression are less well defined. Human cytomegalovirus

77 (CMV) is a beta-herpesvirus that persists within the majority of the human population. During

78 infection of an immunocompetent host, CMV has a protracted acute phase and then establishes

79 a life-latent infection, which is marked by sporadic subclinical reactivation events. CMV

80 establishes latency in CD34+ hematopoietic progenitor cells (HPCs) and is carried through 
Buehler et al. 4

81 differentiation in cells of the myeloid lineage, including CD14+ monocytes (1). During latency in

82 experimental models, CMV genes are expressed broadly but at very low levels $(2,3)$ and

83 replication is restricted. Reactivation in immunodeficient individuals, such as stem cell or solid

84 organ transplant recipients, is a major cause for morbidity and mortality (4-6). Additionally, CMV

85 reactivation in patients undergoing intensive chemotherapy treatments can cause severe

86 pathologies, including pneumonia, enteritis, blindness, and deafness $(7,8)$. Currently, there is no

87 vaccine and existing antivirals have toxicity issues and cannot target latently infected cells.

88 Understanding the molecular mechanisms that define and control the latent CMV infection is

89 critical for the development of novel strategies to target the latent infection.

91 Virus manipulation of host cell signaling during infection of hematopoietic cells provides the

92 means by CMV ensures survival of the infected cells and control differentiation and reactivation

93 (9-14). Epidermal growth factor receptor (EGFR) signaling is a key component of the molecular

94 switch regulating the establishment of latency and reactivation of viral replication (15). In CD34+

95 HPCs, CMV stimulates EGFR during entry and these initial signaling events are important for

96 the establishment of latency (16). EGFR also serves as an entry receptor for CMV into

97 fibroblasts (17), although sustained EGFR signaling represses productive replication (15).

99 The CMV UL135 and UL138 gene products antagonistize on another in regulating latency and 100 reactivation (18). UL138 is suppressive to virus replication and critical for the establishment of 101 latency, whereas UL135 is important for reactivation. UL135 functions, in part, by overcoming 102 the suppressive effects of UL138, which otherwise block the initiation of viral replication from 103 infectious genomes Accordingly, UL135 and UL138 gene products both interact with EGFR, but 104 have opposing effects on the regulation of EGFR trafficking and signaling (15). UL135, reduces 
Buehler et al. 5

105

106

107

108

109

110

111

112

113

114

115

116

117

118

119

120

121

122

123

124

125

126

127

total and cell surface levels of EGFR. UL135 regulates EGFR trafficking and signaling through its interactions with the host adapter proteins for the Cbl E3 ubiquitin ligase, Abelson interacting protein 1 (Abi1), CIN85 and CD2AP $(15,19)$. Mutations in UL135 ablating these host interactions restore EGFR levels in infected fibroblasts and diminish reactivation from latent infection (19). The mechanism by which UL138 regulates EGFR is less clear. However, in contrast to UL135, UL138 increases cell surface levels of EGFR in productively infected fibroblasts and is important for sustained EGFR signaling activity (15). The interactions between UL135 and Abi-1 and CIN85/CD2AP are required for reactivation, directly linking UL135mediated degradation of EGFR to reactivation (20).

In this study, we defined the PI3K/AKT and MEK/ERK pathways downstream of EGFR as important to the establishment of latency using our experimental CD34+ HPC model. By contrast, the PLCY and STAT pathways did not impact latency in our system. Additionally, EGFstimulation increased UL138 gene expression, suggesting that EGFR signaling impacts latency gene expression. We mapped consensus binding sites for the early growth response factor 1 (EGR1) transcription factor upstream of UL138. EGR1 is highly expressed in CD34+ HPCs and is required to maintain stemness (21). Here, we show that EGR1 binds to sites within the UL133-UL138 gene locus and stimulates UL138 gene expression and these sites are required to maintain latency in CD34 ${ }^{+}$HPCs. From these findings a positive feedback model emerges where by UL138 sustains EGFR signaling and EGFR signaling stimulates EGR1, which then drives UL138 gene expression. Disruption of EGR-1 regulation of UL138 expression results in a loss of latency and the virus replicates. This work defines one mechanism by which EGFR signaling impacts viral gene expression to regulate CMV latency and reactivation. 
Buehler et al. 6

\section{RESULTS}

130

131

132

133

134

135

136

137

138

CMV downregulates total and cell surface levels of EGFR. We previously demonstrated that CMV modulates EGFR total and cell surface levels during infection in fibroblasts (productive infection) and CD34+ HPCs (site of latency)(15). In fibroblasts, we demonstrated that EGFR surface and total levels decrease substantially by 48 hours post infection (hpi). To further understand the regulation of EGFR during productive infection, we analyzed surface and total levels of EGFR in fibroblasts over a time course of infection from 0-72 hpi. Fibroblasts were infected with the TB40/E strain expressing GFP as a marker for infection (22), which serves as the parental/wild-type (WT) virus for all studies and EGFR surface levels were measured by flow cytometry (Fig. 1A). EGFR surface levels began to decrease by $12 \mathrm{hpi}$ and were reduced to $\sim 60 \%$ of uninfected cells by $24 \mathrm{hpi}$, and remained between 50 and $60 \%$ of uninfected cells for the remainder of the infection time course. Analysis of total EGFR levels over the same time course indicated that total EGFR levels were reduced to $40 \%$ and $20 \%$ of uninfected cells by 48 and 72 hpi, respectively (Fig. 1B). These findings are consistent with our previous work demonstrating the downregulation of EGFR during the productive cycle of infection $(15,20)$ and extend those observations by defining the onset of this downregulation as within the early stages of infection.

\section{CMV was previously shown to transcriptionally downregulate EGFR $(23,24)$. While UL135} downregulates, total levels of EGFR $(15,20)$, disruption of UL135 or its interaction with host proteins does not fully restore EGFR to uninfected cell levels. This might be explained by a transcriptional downregulation of EGFR. However, we did not detect any significant alteration in EGFR mRNA levels by quantitative reverse transcriptase PCR (RT-qPCR) over the time course of infection(Fig. 1C). The lack of a transcriptional downregulation in our study may refelect 
Buehler et al. 7

difference in the virus strain used for infection or the cells type, and leaves open the possibility that other viral factors contribute to the diminishment of EGFR levels.

We previously observed a re-localization of EGFR to the viral assembly compartment during productive replication (15). To determine the timing of EGFR re-localization, EGFR subcellular localization was determined in TB40/E infected fibroblasts at (Fig. 1D). IE2 was used to mark infected cells. In uninfected cells ( 0 hpi) EGFR staining is localized at the plasma membrane and distributed in puncta throughout the cytoplasm. Although, the distribution of EGFR was not dramatically altered between 6 and $12 \mathrm{hpi}$, a large portion of EGFR re-localized at $24 \mathrm{hpi}$ to a juxta-nuclear region and is maintained there. We previously demonstrated that this juxta-nuclear localization is proximal with markers, GM130 and pp28, for the viral assembly compartment (15). However, this result indicated that EGFR is re-localized at early times in infection prior to the formation of the assembly compartment.

\section{EGFR and downstream pathways are inhibited by CMV as replication progresses. To}

determine how CMV productive infection impacts EGFR signaling and pathways downstream of EGFR, we analyzed phosphorylation of EGFR, MEK1/2, ERK1/2, STAT3, PLCY, and AKT at steady state or following 30 min of EGF stimulation in infected fibroblasts using a EGFR signaling array (PathScan, Cell Signaling Technologies). At steady state, phosphorylation of EGFR at T669, Y845, and Y1068 was increased relative to uninfected cells. However, EGFR was less responsive to EGF stimulation, marked by decreased phosphorylation on T669, Y845, and $\mathrm{Y} 1068$ relative to uninfected, stimulated cells (Fig. S1A). Infection did not alter phosphorylation of EGFR Y998. While basal activity of MEK1/2, ERK1/2, and AKT was not altered by infection in unstimulated cells, EGF-stimulated phosphorylation of MEK1/2 (S221 or 
Buehler et al. 8

177

178

179

180

181

182

183

184

185

186

187

188

189

190

191

192

193

194

195

196

197

198

199

200

S217/221, Fig. S1B) and AKT (S473, Fig. S1C) was reduced in infected cells relative to uninfected cells. CMV infection did not affect phosphorylation and activation of STAT3 (Y705), PLCY1 (S1248) or AKT (T308) in response to EGF stimulation (Figure S1C). These results suggest that MEK/ERK and AKT signaling are the primary pathways downstream of EGFR that are suppressed by CMV infection.

To further analyze the inhibition of both AKT and MEK1/2 pathways by CMV, we monitored their activation over a time course of infection. Serum starved, infected fibroblasts were pulsed with EGF ligand over a time course following infection $(0,12,24,48$, and $72 \mathrm{hpi})$ and cell lysates were harvested at 0,15 and 30 minutes following each EGF pulse to analyze the phosphorylation of EGFR (Y1068), AKT (S473), and MEK1/2 (S217/221) (Fig. 2A). In uninfected fibroblasts, EGFR, AKT and MEK1/2 phosphorylation was induced by 15 min post EGF stimulation, as expected. In fibroblasts infected for 12 hours, pEGFR, pAKT, pMEK1/2 induction was unchanged from uninfected cells. In contrast, the levels of all three phosphorylation markers decreased significantly after EGF stimulation with a reduction of pMEK1/2 by 24 hpi and both pEGFR and pAKT by 48 hpi, relative to uninfected fibroblasts (Fig. 2B). By 72 hpi, pEGFR and pAKT was undectectable in infected cells (Fig. 2A). Induction of pMEK1/2 in response to EGF stimulation is undetectable relative to basal levels by $24 \mathrm{hpi}$. Together these data indicate that EGFR and both the MEK/ERK and PI3K/AKT downstream signaling nodes become progressively less responsive to stimulation in the productive infection.

$\mathrm{PI3K} / \mathrm{AKT}$ and MEK/ERK pathways suppress viral replication for latency. Work by the Chan and Yurochko groups have demonstrated that PI3K signaling is important to survival of CMV-infected monocytes $(10,25)$. Further, we previously demonstrated that inhibition of EGFR 
Buehler et al. 9

201

202

203

204

205

206

207

208

209

210

211

212

213

214

215

216

217

218

219

220

221

222

223

224

225 or PI3K increases CMV replication in fibroblasts and reactivation in $\mathrm{CD}^{+} 4^{+}$hematopoietic progenitor cells (HPCs) (15). To further investigate how pathways downstream of EGFR impact CMV replication and latency, we used chemical inhibitors of the MEK/ERK, STAT, PI3K/AKT, and PLCY pathways. The efficacy of each inhibitor at the chosen concentration was confirmed by analyzing phosphorylation over a 5 day time course (Fig. S2). Fibroblasts were treated with inhibitors at 1 day post infection so as not to interfere with viral entry $(16,26,27)$ and viral titers were measured at 8 dpi (Fig. 3A). Inhibition of PI3K (LY294002) or AKT (MK-2206) increased viral titers by 7.6 and 7 -fold, respectively, in comparison to the vehicle control, similar to what we have previously reported with EGFR inhibition (15). In contrast, inhibition of STAT1 (Fludarabine) or STAT3 (S3I-201) decreased virus production. Loss of viral replication by STAT inhibition has previously been reported with these and similar inhibitors $(28,29)$. The diminishment of virus replication was not related to cytotoxicity, as the monolayers stayed intact. Inhibition of MEK1/2 (Binimetinib), ERK1/2 (SCH772984), or PLCY (U73122) did not alter virus titers relative to the vehicle control. These data confirm that PI3K/AKT pathways are suppressive to virus replication and demonstrate that MEK/ERK and PLCy pathways are dispensable for productive infection in fibroblasts.

To determine the importance of the signaling pathways downstream of EGFR to latency and reactivation, we analyzed the impact of each inhibitor on latency and reactivation in CD34+ HPCs.. Infected (GFP+) CD34+ HPCs were isolated by fluorescent activated cell sorting (FACS) and co-cultured for 10 days in long-term bone marrow cultures using a bone marrow stromal cell support that has been shown to maintain hematopoietic cell progenitor phenotype and function (30). This period in long-term bone marrow culture allows for the establishment of CMV latency. At $10 \mathrm{dpi}$, half of the cells were seeded by limiting dilution into co-culture with fibroblasts in a cytokine-rich media to promote myeloid cell differentiation and reactivation. The 
other half of the culture was lysed and seeded by limiting dilution in parallel onto fibroblasts to

227 quantify virus formed during the latency period (pre-reactivation) (31). Reactivation resulted in a

$228 \quad 2-3$ fold increase in the frequency of infectious centers relative to the pre-reactivation control

229 (DMSO control, Fig. 3B). Inhibition of MEK/ERK with Binimetinib or SCH772984 increased the

230 frequency of infectious centers by at least 2-fold in both the pre-reactivation and reactivation

231 condition relative to their respective DMSO control. Inhibition of PI3K (LY294002) induced a 4-

232 fold increase in infectious centers in the pre-reactivation and an almost 10-fold increase in

233 infectious centers in the reactivation. Inhibition of AKT (MK-2206) resulted in a loss of latency

234 with a 10-fold increase in the frequency of infectious centers in the pre-reactivation and a 5.5-

235 fold increase in the reactivation, relative to DMSO controls. By contrast, inhibition of STAT3 and

236 PLCy did not significantly alter infectious centers produced prior to or following reactivation

237 relative to the DMSO controls. Fludarbine was not used in CD34+ HPCs because a non-toxic

238 dose could not be found. These results indicate that the MEK/ERK and PI3K/AKT pathways

239 each contribute to the maintenance of CMV latency and inhibition of these pathways enhances

240 reactivation, while we find no role for STAT3 or PLC $\gamma$.

EGF stimulation drives expression of the UL138 latency determinant. Collectively, our work demonstrates a requirement for EGFR and downstream PI3K/AKT and MEK1/2 signaling

244 pathways for the suppression of virus replication to maintain latency in CD34+ (Fig. 2B) (15).

245 However, the mechanisms by which host signaling impacts infection is not know. While the 246 effect of EGFR signaling on cellular gene expression (32) might impact virus replication and

247 latency, we hypothesized that EGFR signaling might also impact viral gene expression and,

248 specifically, the expression of genes required for latency. 
251 locus, we monitored expression of the immediate early genes UL122 and UL123 (IE2 and IE1,

252 respectively), UL135, and UL138 in serum starved, infected fibroblasts over a time course

253 following EGF stimulation (Fig. 4A). UL138 protein accumulation increased by $75 \%$ at $1 \mathrm{~h}$

254 following EGF stimulation relative to unstimulated cells (Fig. 4A). UL138 protein levels remained

255 elevated for up to 6h post EGF pulse. In contrast, neither UL135 nor IE1/2 levels changed in

256 response to EGF-stimulation.

258 To begin to understand how EGFR signaling might affect UL138 expression, we used

259 PhysBinder to identify putative transcription factor binding sites within the UL 133-UL 138 locus

260 that are regulated by EGFR signaling (33). To minimize the potential for false positives, we used

261 the Max Precision setting and identified two binding sites for early growth response factor 1

262 (EGR1) within the UL135 open reading frame (ORF) upstream of UL138 (Fig. 4B). To confirm

263 binding of EGR1 to these sites, we transduced fibroblasts with lentiviruses expressing EGR1

264 fused to a $3 x$ Flag epitope tag ( $E G R 1_{3 x F l a g}$ ) and infected the cells with either a wild-type or a

265 UL133/8 deletion mutant (negative control; NC) TB40/E viruses. At 48 hpi, samples were

266 processed for chromatin immunoprecipitation (SimpleChIP ,Cell Signaling Technologies) with

267 normal IgG or antibodies to either EGR1 or Histone $3(\mathrm{H} 3)$ and binding was detected by PCR

268 with site-specific primers (Fig. 4C). The EGR1 antibody precipitated sequences in the wild-type

269 infection for both binding sites by PCR; but not in the NC or lgG control. These results indicate

270 that EGR1 interacts with both site 1 and site 2. Interesting, both PI3K/AKT and MEK/ERK

271 pathways induce EGR1 (34-36)(Fig. 4D). EGR-1 is of particular interest because it is highly

272 expressed in hematopoietic cells, a site of CMV latency $(21,37)$. EGR1 is required to maintain

273 stem cell quiescence and retention in the bone marrow and must be downregulated for

274 hematopoietic differentiation and migration out of the bone marrow. Therefore, we hypothesized 
Buehler et al. 12

275

276

277

278

279

280

281

282

283

284

285

286

287

288

289

290

291

292

293

294

295

296

297

298 that EGR1 might stimulate the transcription of RNAs encoding UL138 that we previously mapped to initiate downstream of the UL135 ORF (38-40). The presence of putative EGR1 binding sites upstream of these transcripts suggests the existence of a promoter element in this region to regulate UL138 expression; this element has not been mapped yet. In this case, EGR1 binding would be expected to induce UL138, but not UL135 gene expression, consistent with our result in Figure 4A.

To determine if EGR1 is sufficient to induce UL138 expression we transduced fibroblasts with lentivirus expressing either EGR1 $1_{3 \times F l a g}$ or empty vector and infected cells with TB40/E. EGR1 overexpression increased UL 138 expression in infected cells by 4 -fold, while IE 1 and 2 proteins were unaffected (Fig. 4E). To ensure that EGR1 activity is not priming UL138 expression from a more distal promoter site, we co-transfected HEK-293T cells with a plasmid containing the entire UL133-UL138 locus in a promoterless vector backbone (UL133/8) and either the EGR1 $1_{3 x \text { Flag }}$ expression construct or an empty control. UL138 can be expressed from this vector due to the presence of an IRES upstream of UL138 (38)however, UL138 protein levels increased 3.5-fold in cells overexpressing EGR1 relative to the empty vector control (Fig. 4F). These results indicate that EGR1 expression is sufficient to stimulate UL138 expression from an unmapped regulatory element encoded with the UL133/8 locus.

Mikell et al. have identified a CMV micro RNA transcribed within the US22 open reading frame (miR-US22) that targets EGR1, resulting in a 2 to 5-fold decrease in EGR1 protein levels depending on cell type and is required for reactivation (41). A miR-US22-mutant ( $\Delta$ US22) virus results in increased expression of EGR1 and fails to reactivate. We hypothesized $\Delta$ US22 would also have increased expression of UL138. To test this, we infected fibroblasts with a wild type or 
Buehler et al. 13

$\Delta$ US22-mutant TB40/E virus and pulsed them with EGF for 1 hour at different time points (Fig. 4G). At both $3 \mathrm{dpi}$ and $4 \mathrm{dpi}$, UL138 was increased by $\sim 25 \%$ in the $\Delta \mathrm{US} 22$-mutant virus infection relative to WT infection. The increase in UL138 protein levels corresponded to increased EGR1 protein levels in the context of $\Delta U S 22$ virus infection. This result indicates that UL138 gene expression is induced by EGFR signaling through the induction of EGR1 and suggests an epistatic relationship between UL138 and US22 and EGR1 in regulating infection.

\section{CMV maintains EGR1 levels during latent infection, but reduces its expression during}

productive replication. To determine how EGR1 is regulated during CMV latent infection, we analyzed EGR1 mRNA expression in TB40/E-infected CD34 ${ }^{+}$HPCs derived from two donors at 2 and 6 dpi by RNA sequencing (2). In each donor, EGR1 expression increased following CMV infection from 2 to 6 dpi by 3 -fold(Fig. 5A). By contrast, the expression of two related genes belonging to the same zinc-finger transcription factor family, EGR2 and EGR3, were unchanged by CMV infection. Additionally, CMV did not affect expression of Wilms tumor 1 (WT1) a factor that binds competitively to the EGR1 consensus sequence to antagonize EGR1 transcriptional control of genes, including EGFR $(42,43)$. By contrast, EGR1 is suppressed 3-fold during replication in fibroblasts following an initial induction (Fig. 5B) that is likely due to the stimulation of EGFR at the cell surface during viral entry $(16,44)$. Further, EGR1 is strongly induced in serum starved, uninfected fibroblasts and infection diminishes this induction by 7 -fold (Fig. 5C).

The lack of responsiveness of EGR1 to EGF stimulation in infected cells likely reflects diminished EGFR levels and signaling in the context of infection beginning at $24 \mathrm{hpi}$ (Figs. 1 and 2). These findings are consistent with the differential regulation of EGFR during productive and latent states of viral infection which we previously described (15). 
Buehler et al. 14

\section{EGR1 binding in the UL133-UL138 region induces UL138 protein accumulation. To}

validate the EGR1 binding sites upstream of $U L 138$, we introduced silent mutations into wobble codons within site 1 or site 2 by site directed mutagenesis in the promoterless UL133/8 vector to generate $\Delta$ Site 1 or $\Delta$ Site 2 constructs. HEK-293T cells were co-transfected with an empty vector or EGR1-Flag expression vector (EGR1 $\left.{ }_{3 \times F L A G}\right)$ and either WT UL133/8 or $\Delta$ Site 1 or $\Delta$ Site 2. UL138 protein levels in cells expressing EGR1 $1_{3 \times F l a g}$ were normalized to that in cells transfected with empty vector (Fig. 6A). EGR1 overexpression induced UL138 protein accumulation 4-fold from the WT UL133/8 construct; however mutation of either Site 1 or Site 2 resulted in 2-fold reduces levels of UL138 protein.

To further validate the role of the EGR-1 binding sites in regulating UL 138 expression, we analyzed UL138 protein levels in HEK 293T cells transfected with the WT UL133/8 or $\Delta$ Site1+2 promoterless vectors and EGR1 siRNAs or miR-US22 to knocked down EGR1 (Fig. 6B). Knockdown of EGR1 either with the EGR1 siRNA or miR-US22 decreased UL138 protein levels by $30 \%$ in cells containing the wild-type UL133/8 plasmid. However, EGR1 knockdown had no effect on UL138 protein accumulation in cells where site 1 and site 2 was disrupted. Taken together, these results indicate the importance of EGR1 binding sites to EGR1-mediated induction of UL138 expression.

We next engineered the EGR1 binding site disruptions into the TB40/E genome cloned as a bacterial artificial chromosome, resulting in TB40/E- $\Delta E G R 1_{\text {Site } 1}$ and TB40/E- $\Delta E G R 1_{\text {Site } 2 .}$ We confirmed the disruption of EGR1 binding sites by sequencing (Fig. S3). We evaluated each virus for its ability to replicate in fibroblasts by multi-step growth curves. Each virus replicated

with wild-type kinetics and to wild type titers (Fig. 7A), indicating that the mutations introduced to 
Buehler et al. 15

disrupt EGR1 binding to the UL133-UL138 region do not affect productive virus replication in fibroblasts.

To determine if either EGR1 binding site mutation affected UL138 expression in the context of infection, we infected fibroblasts with TB40/E-WT, $-\Delta \mathrm{EGR} 1_{\text {Site } 1}$ or $-\Delta \mathrm{EGR} 1_{\text {Site } 2}$, and measured UL138, UL135, and IE1/IE2 protein levels at 48 hpi by immunoblot (Fig. 7B). Disruption of Site 1, but not Site 2 , decreased UL138 protein levels by 50\%. While, IE protein levels were unaffected, we detected a profound loss of UL135 protein in the TB40/E- $\triangle E G R 1_{\text {Site } 2}$ infection. This loss was evident in multiple independent clones of this virus. Given the importance of UL135 on reactivation (18), we moved forward with only the TB40/E- $\Delta E G R 1_{\text {Site } 1}$ mutant virus.

To confirm the loss of EGR1 binding to $\Delta \mathrm{EGR} 1_{\text {Site } 1}$ in the context of infection, we transduced fibroblasts with EGR1 $1_{3 \times F L A G}$ lentivirus and infected with either WT or TB40/E- $\triangle E G R 1_{\text {site } 1}$ mutant virus. EGR1 was immunoprecipitated (SimpleChIP, Cell Signaling Technologies) and binding to site 1 was quantified by qPCR using primers flanking site 1 . EGR1 precipitated 50-fold more site 1 sequence in the WT-virus infection relative to the IgG control (Fig. 7C). Infection with TB40/E$\Delta \mathrm{EGR} 1_{\text {Site } 1}$ resulted in a 4-fold reduction in EGR1 binding relative to wild-type. We also analyzed binding of endogenous EGR1 to Site 1 in fibroblasts infected with either TB40/E-WT or TB40/E- $\Delta \mathrm{EGR} 1_{\text {Site } 1}$ and stimulated with EGF for $1 \mathrm{~h}$ to induce EGR1 (Fig. 7D). As in Figure 7C, EGR1 binding to site 1 was increased 4-fold relative to $\lg$ G control and was reduced nearly 4fold in TB40/E- $\Delta \mathrm{EGR} 1_{\text {Site } 1}$ infection relative to . Taken together, these data demonstrate that disruption of the EGR1 binding site 1 in the UL133/8 regions disrupts EGR1 binding and EGR1mediate induction of UL138 expression. 
Buehler et al. 16

371 EGR1-stimulation of UL138 is required for CMV latency. To determine if EGR1 binding is

372 important for CMV latency we infected CD34+ HPCs with either TB40/E-WT or TB40/E-

$373 \Delta \mathrm{EGR} 1_{\text {Site } 1}$ mutant virus. At $24 \mathrm{hpi}$, pure populations of infected HPCs $\left(\mathrm{GFP}^{+} \mathrm{CD} 34^{+}\right)$were

374 isolated and seeded into transwells above a stromal cell support for long-term culture. After 10

375 days of long-term culture, the cultures were split and half were mechanically lysed. We then

376 seeded the lysate or live cells by limiting dilution in parallel onto fibroblasts. $\mathrm{GFP}^{+}$wells were

377 scored 14 days later to determine the frequency of infectious centers present at the time of lysis

378 (pre-reactivation) or resulting from reactivation, as described for Figure 3B. Reactivation of

379 TB40/E-WT produced a 3-fold increase in the frequency of infectious centers relative to the pre-

380 reactivation control (Fig. 8). In contrast, TB40/E- $\Delta E G R 1_{\text {Site } 1}$ infection resulted in a loss of

381 latency and equal frequencies of infectious centers were measured prior to and following

382 reactivation. The loss of latency with the TB40/E- $\Delta \mathrm{EGR} 1_{\text {Site } 1}$ mutant is a similar phenotype as a

383 UL138 ${ }_{\text {nul }}$ mutant virus in CD34 ${ }^{+}$HPCs (18). While the cell numbers required for immunoblots of

384 viral proteins is prohibitive, the loss of latency phenotypes are consistent with diminished

expression of UL138. Further, these results are consistent with our finding that inhibition of

EGFR, PI3K, or ERK1/2 signaling promotes the reactivation of viral replication (Fig. 3B).

\section{DISCUSSION}

389 To regulate the establishment of latency and the reactivation of replication, all herpesviruses

390 rely on and manipulate cellular signaling pathways to regulate their viral lifecycle. CMV targets

391 and manipulates EGFR and its downstream pathways to achieve this goal $(11,13,15,19,24$,

392 26). Stimulation of EGFR signaling upon entry into hematopoietic cells is important to establish

393 an environment to support latency in CD34+ HPCs $(10,16,45)$. While EGFR is downregulated

394 during the replicative cycle, targeting EGFR provides CMV with access to cellular processes 
involved in differentiation, proliferation, motility, immune signaling, and DNA repair (46-50). By incorporating EGFR signaling into CMV entry, latency, and reactivation of viral replication the virus maintains a firm grasp on the receptor and its signaling cascades (13). From the findings of this study, we propose a model whereby EGFR signaling through MEK/ERK and PI3K/AKT pathways drives UL138 expression through the induction of EGR1 to suppress viral replication for latency (Fig. 9). As such, the high levels of EGR1 in CD34 ${ }^{+}$HPCs likely primes these cells for expression of UL138 upon infection and the establishment of latency upon infection (21). Combined with our previous findings that UL138 maintains EGFR surface levels (15), we propose a model by which EGFR and UL138 form a positive feedback loop to promote and maintain CMV latency. By disrupting the feedback loop, with either chemical inhibitors or preventing EGR1 binding, the virus is unable to maintain latency and replicates. We have previously shown that UL135 opposes UL138 in targeting EGFR for turnover and reactivation $(15,19)$. Here, we demonstrate that CMV miR-US22 also counteracts UL138 regulation of EGR1 by targeting EGR1.

We demonstrate that EGFR activation of the MEK/ERK and PI3K/AKT signaling axes regulates gene expression of UL138 through EGR1 binding to an unmapped element in the UL133-UL138 locus that stimulates the expression of $U L 138$, which in turn suppresses virus replication for latency. PI3K/AKT and MEK/ERK signaling pathways are common targets in herpesvirus infection and their sustained signaling maintains latency. Herpes simplex virus 1 (HSV-1) activates PI3K activity through stimulation of neural growth factor to maintain persistence (51). Inhibition of P13K stimulates HSV-1 reactivation, but full reactivation also requires C-Jun Nterminal kinase (JNK), a MAPK family member, signaling to induce histone phosphorylation on viral promoters to de-repress HSV-2 gene expression (52). Also, HSV-1 proteins VP11/12 interact with Src-family kinases, Grb2, Shc, and p85 through a tyrosine-binding motif in order to 
Buehler et al. 18

420

421 protein kinase suppresses ERK signaling to promote viral replication (54). Epstein-Barr virus

422 (EBV) latency membrane protein-1 (LMP-1) promotes both EGFR protein levels and activation

423 of STAT3 and ERK signaling pathways (55-57), while LMP-2A activates PI3K/AKT signaling

$424(58,59)$. Additionally, LMP-2A also promotes cellular survival through ERK activation mediating

425 proteosomal degradation of proanoikis mediator Bim (60). Lastly, Kaposi's sarcoma-associated

426 herpesvirus (KSHV) latent infection promotes AKT/PI3K activation (61). However, in contrast to

427 CMV infection, KSHV activates MEK/ERK signaling to promote its reactivation and inhibition of

428 MEK/ERK signal suppresses ORF50 expression and KSHV reactivation $(62,63)$. These

429

430

431

432

433

434

435

436

437

438

439

440

441

442 The role of EGR1 in promoting UL138 expression during CMV infection (Fig. 4 and Fig. 6) is

combined findings illustrate the significance of PI3K/AKT and MEK/ERK signaling pathways to the regulation of herpesvirus programs of latency and replication.

EGR1 induces UL138 gene expression, but our results indicate that $U L 138$ is not dependent on EGR1. UL138 is expressed from the 3' end of a series of polycistronic transcripts encoded within the UL133-UL138 locus and differ only in their 5' ends $(38,40)$. Therefore, while EGR1 contributes to heightened UL138 expression under specific contexts of infection in the cell, there are other mechanism that allow for constitutive or inducible UL138 expression. One additional contributor to UL138 expression is an IRES element that overlaps the UL136 ORF. This element is upstream of the EGR1 binding sites and stimulates downstream UL138 gene expression from long polycistronic transcripts $(38,40)$. Therefore, multiple transcription and translational regulatory mechanisms control the expression of UL138.

\footnotetext{
particularly intriguing because CD34 ${ }^{+}$HPCs express high levels of EGR1 during maintenance in
} 
Buehler et al. 19

444 the bone marrow (21). As such, CD34+ cells are predisposed to promote UL138 expression

445 upon CMV infection to suppress viral replication. This observation is one explanation for why we

446 have only detected UL138 protein, but not other UL133-UL138 proteins, in latently infected

447 CD34 ${ }^{+}$HPCs (39). Upon differentiation of CD34 ${ }^{+}$HPCs EGR1 expression is abolished (21), a

448 requirement for the differentiation and migration of stem cells out of the bone marrow.

449 Therefore, decreased level of UL138 as a result of diminished EGR1 combined with myeloid

450 differentiation, which would predispose the cells towards reactivation. By contrast, EGR1 levels

451 are low in sites of productive replication, such as fibroblasts. CMV-mediated suppression of

452 EGFR, MEK/ERK and PI3K/AKT signaling would result in the further suppression of EGR1

453 expression for replication (Fig. 2 and 5C). Additionally, the CMV miroRNA, miR-US22, targets

454 EGR1 messages and is necessary for the reactivation from latency(41). In collaboration with the

455 Nelson group, we show that miR-US22 targeting of EGR1 reduces UL 138 expression. Finally,

456 CMV replication in fibroblasts stimulates WT1 expression (24), which competes antagonistically

457 for EGR1 targets, including $\operatorname{EGFR}(42,64)$, and indicates another mechanism by which the virus

458 antagonizes EGFR/EGR1 signaling for productive infection. Taken together, our results

459 demonstrate that EGR1 is an important target in CMV infection and its expression is targeted

460 through multiple mechanisms to promote viral replication.

462 EGR1 regulates viral gene expression in the context of other herpesvirus infections. In HSV-1, 463 EGR1 binding sites are located within the introns for both ICP22 and ICP4 (65). In contrast to 464 our findings, EGR1 inhibits both ICP4 and ICP22 by blocking SP1 binding sites and recruiting 465 the co-repressor Nab2 (65). The authors predict that the inhibition of both of these immediate 466 early genes would promote HSV-1 gene silencing for the establishment of latency. In further 467 contrast to CMV, during KSHV infection glycoprotein B suppresses ERK1/2 signaling to decrease expression of ORF50 to promote the establishment of latency(63). Similar to KHSV, 
EBV transactivator ZTA upregulates EGR1 by both interacting with its promoter and by

470 increasing ERK signaling in order to promote viral reactivation(66). While the mechanism by

471 which each herpesvirus utilizes EGR1 to control viral latency and replication differs, it is clear

472 that manipulating EGR1 is common feature. These differences may reflect the unique cell types

473 where each herpesvirus establishes latency.

475 Herpesviruses manipulate multiple signaling pathways to control viral latency and to promote 476 viral replication, and understanding the complex interplay between these signaling pathways

477 and the virus is necessary to fully appreciate how these viruses persist. We have shown that

478 viral manipulation of host signaling impacts the control of viral transcription. Putative EGR1

479 binding sites exist throughout the CMV genome and, because EGR1 can either promote or 480 repress gene expression $(64,67)$, it will be important to understand how EGR1 binding to 481 promoters across the genome impact latent and replicative states of infection.

\section{MATERIALS AND METHODS}

Cells. MRC-5 lung fibroblasts (ATCC), HEK293T/17 cells (ATCC), SI/SI stromal cells (Stem Cell

485 Technology), M2-10B4 stromal cells (Stem Cell Technology), and CD34+ HPCs were

486 maintained as previously described (18). Human CD34 ${ }^{+}$HPCs were isolated from de-identified

487 medical waste following bone marrow isolations from healthy donors for clinical procedures at

488 the Banner-University Medical Center at the University of Arizona. Latency assays were

489 performed as previously described $(15,18)$. 
Buehler et al. 21

491 Viruses. Bacterial artificial chromosome (BAC) stocks of TB40/E WT virus expressing GFP

492 from a SV40-promoter was provided as gift from the Szinger lab (22). EGR1 binding mutant

493 viruses were created by two-step, positive-negative selection approach with galK substitution as

494 was previously described $(18,68)$. Both the TB40/E UL133/8 ${ }_{\text {Null }}$ galK intermediate and pGEM-T

495 UL133-UL138 shuttle vector, referred to as UL133/8 plasmid in the results, were created

496 previously and described in Umashankar et al. 2014 (18). EGR1 binding sites were mutated by

497 Phusion PCR mutagenesis using flanking PCR primers to each region with mutations

498 incorporated into the corresponding forward and reverse primers (Table 1). pGEM-T UL133-

499 UL138 plasmids removing EGR1 site 1 ( $\Delta$ Site 1$)$, EGR1 site 2 ( $\Delta$ Site 2$)$, or both EGR1 sites

$500(\Delta$ Site $1+2)$ were created and stocks were maintained in $\mathrm{DH} 10 \mathrm{~B}$ bacteria glycerol stocks.

501 Inserts for BAC recombineering were gel purified from pGEM-T $\Delta$ Site 1 and $\Delta$ Site 2 plasmids

502 digested with EcoRI. Inserts were electroporated into SW102 E. coli containing the TB40/E

503 UL133/8 $8_{\text {Null }}$ galK intermediate as previously described (69). BAC integrity was confirmed by

504 comparing EcoRV digestion of the EGR1 binding site mutant BACs to wild type TB40/E BAC

505 digest. Mutations of EGR1 binding sites in TB40/E- $\Delta E G R 1_{\text {Site } 1}$ and TB40/E- $\Delta E G R 1_{\text {Site } 2}$ were

506 confirmed by Sanger sequencing. Loss of EGR1 binding in TB40/E- $\Delta E G R 1_{\text {Site } 1}$ was confirmed

507 by ChIP-qPCR, described below. TB40/E $\mathrm{E}_{\mathrm{GFP}} \Delta \mathrm{miR}-\mathrm{US} 22$ was created as described in Mikell et

508 al. (41).

509

510 Table 1 Primer sequences

Primer Sequence

$\Delta$ Site 1 Forward

$\Delta$ Site 1 Reverse

$\triangle$ Site 2 Forward

$\Delta$ Site 2 Reverse

pCIG3 EGR1 Forward

pCIG3 EGR1 Reverse
5'- [phos]CCAACCCCGCAGGTGCCGCG-3'

5'-[ [phos]GGGGTGGGTGGCCACC-3'

5'- [phos]CACCCCGATGGTCGGACATCGAGG-3'

5'- [phos]GGGGGGCTAACTCGGAAACCG-3'

5'- ATCGATCGGAATTCCACCATGGCCGCGGCCAAGGCC-3'

5'- GCATGCATTTAATTAATCAGCAAATTTCAATTGTCCTGGGAGAAAAGGTTGC-3' 
Buehler et al. 22

\begin{tabular}{|c|c|}
\hline EGR1 3xFlag Forward & $\begin{array}{l}\text { 5'-[phos]AAGATCATGACATCGATTACAAGGATGACGATGACAAGTGATTAATTAAGGG } \\
\text { GATCCGCCCCTCT-3' }\end{array}$ \\
\hline EGR1 3xFlag Reverse & $\begin{array}{l}\text { 5'- [phos]TATAATCACCGTCATGGTCTTTGTAGTCGCCGCCGCCGCCGCAAATTTCAAT } \\
\text { TGTCCTGGGAGA-3' }\end{array}$ \\
\hline $\begin{array}{l}\text { EGR1 RT-qPCR } \\
\text { Forward }\end{array}$ & 5'-AGCCCTACGAGCACCTGAC-3' \\
\hline $\begin{array}{l}\text { EGR1 RT-qPCR } \\
\text { Reverse }\end{array}$ & 5'-GGGCAGTCGAGTGGTTTG-3' \\
\hline $\begin{array}{l}\text { EGFR RT-qPCR } \\
\text { Forward }\end{array}$ & 5'-CATGTCGATCGACTTCCAGA-3' \\
\hline $\begin{array}{l}\text { EGR1 RT-qPCR } \\
\text { Reverse }\end{array}$ & 5'-GGGACAGCTTGGATCACACT-3' \\
\hline $\begin{array}{l}\text { H6PD RT-qPCR } \\
\text { Forward }\end{array}$ & 5'-GGACCATTACTTAGGCAAGCA-3' \\
\hline $\begin{array}{l}\text { H6PD RT-qPCR } \\
\text { Forward }\end{array}$ & 5'-CACGGTCTCTTTCATGATGATCT-3' \\
\hline Site 1 ChIP Forward & 5'- CGCCGACGGAGCCGA-3' \\
\hline Site 1 ChIP Reverse & 5'- TGCACCGCCTTTTCCAAGAGTTC-3' \\
\hline Site 2 ChIP Forward & 5'- AATCTCTCGAAGGTGGGACTCT-3' \\
\hline Site 2 ChIP Reverse & 5'- CTCGGAAACCGACACGATAGG-3' \\
\hline
\end{tabular}

512 Plasmids and Lentiviruses. pDONR221 containing EGR1 cDNA was purchased from DNASU 513 (Arizona State University; Phoenix, Az). EGR1 was PCR amplified from the pDONR221 plasmid 514 with pCIG3 EGR1 forward and reverse primes and inserted into pCIG3 plasmid at Pacl and 515 EcoRI digestion sites. Addition of a 3xFlag epitope tag was done by Phusion PCR mutagenesis 516 EGR1 3xFlag Forward and Reverse primers EGR1 $1_{3 x F l a g}$ Forward and Reverse sequences. All 517 plasmid inserts were verified through Sanger sequencing and maintained in $\mathrm{DH} 10 \mathrm{~B}$ glycerol 518 stocks. EGR1 $1_{3 \times F l a g}$ lentivirus was created by cotransfecting pCIG3 EGR1 ${ }_{3 \times F L A G}$, pMD2.G, and 519 psPAX2 (Addgene \#12259 and 12260; Trono Lab) into HEK293T/17 cells with polyethylenimine 520 (Polysciences) and collected supernatants at 48 and $72 \mathrm{~h}$ post transfection. Plasmid 521 transfections were carried out in HEK293T/17 cells using PEI at $1 \mu \mathrm{g}$ of DNA to $3 \mu \mathrm{g}$ PEI.

522 Plasmid encoding shRNA of EGR1 was described in Mikell et al. (41).

523 Table 2 Antibody description and Sources 


\begin{tabular}{|c|c|c|c|}
\hline Alexa Fluor 546 anti rabbit & goat & Molecular Probes & IF: $1: 7,000$ \\
\hline Alexa Fluor 647 anti mouse & goat & Molecular Probes & IF: $1: 7,000$ \\
\hline Brilliant Violet 421 EGFR & mouse & BioLegend & Flow $5 \mu \mathrm{L} / 1 \times 10^{6}$ cells \\
\hline Dylight 700 conjugated anti mouse & goat & Pierce & Western: 1:12,000 \\
\hline Dylight 800 conjugate anti rabbit & goat & Pierce & Western: 1:12000 \\
\hline EGFR (D38B1) & rabbit & Cell Signaling & Western 1:10,00; IF 1:50 \\
\hline EGR1 (44D5) & Rabbit & Cell Signaling & $\begin{array}{l}\text { Western } 1: 1,000 \\
\text { ChIP } 10 \mu \mathrm{L} / 4 \times 10^{6} \text { cells }\end{array}$ \\
\hline EGR1 & rabbit & Bethyl & Western 1:1,000 \\
\hline Flag (D655B) & rabbit & Cell Signaling & Western 1:1,000 \\
\hline GAPDH (6C5) & mouse & Abcam & Western $1: 15,000$ \\
\hline HRP anti-mouse & goat & Jackson ImmunoResearch & Western: 1:5000 \\
\hline HRP anti-rabbit & goat & Jackson ImmunoResearch & Western: 1:5000 \\
\hline IE1 (8B1.2) & mouse & Millepore Sigma & Western: 1:40,000 \\
\hline $\mathrm{IE} 1 / 2(3 \mathrm{H} 4)$ & mouse & Tom Shenk; Princeton University & Western 1:1,000 \\
\hline IE2 & mouse & Tom Shenk; Princeton University & IF 1:50 \\
\hline IgG, Normal & rabbit & Cell Signaling & ChIP $2 \mu \mathrm{g} / 4 \times 10^{6}$ cells \\
\hline Histone H3 (D2B12) & rabbit & Cell Signaling & ChIP $10 \mu \mathrm{L} / 4 \times 10^{6}$ cells \\
\hline PE conjugated CD34 & mouse & BD Biosciences & Flow $20 \mu \mathrm{L} / 1 \times 10^{6}$ cells \\
\hline phospho-AKT (S473; D9E) & rabbit & Cell Signaling & Western 1:2000 \\
\hline phospho-EGFR (Tyr1068; D7A5) & rabbit & Cell Signaling & Western 1:1000 \\
\hline $\begin{array}{l}\text { phospho-p44/42 MAPK (ERK1/2) } \\
\text { (Thr202/Tyr204) (D13.14.4E) }\end{array}$ & rabbit & Cell Signaling & Western 1:2000 \\
\hline phospho-MEK1/ (S217/221; 41G9) & mouse & Cell Signaling & Western 1:2000 \\
\hline UL135 & rabbit & Open Biosystems ${ }^{a}$ & Western $2 \mu \mathrm{g} / \mathrm{mL}$ \\
\hline UL138 & rabbit & Open Biosystems $^{a}$ & Western $2 \mu \mathrm{g} / \mathrm{mL}$ \\
\hline a-Tubulin (DM1A) & mouse & Sigma & Western 1:10000 \\
\hline
\end{tabular}

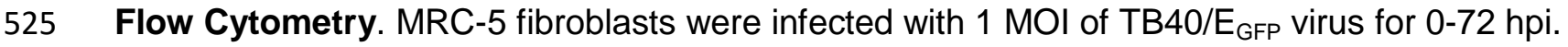

526 Cells were lifted off the plates, fixed in $2 \%$ Formaldehyde in PBS for 30 min, and washed with

527 excess PBS. Cells were then stained with Brilliant Violent 421-conjugated ms $\alpha$-EGFR

528 (Biolegend; Table 2). Samples were gated for intact GFP ${ }^{+}$cells and geometric mean of

529 fluorescence intensity (geoMFI) was measured using a BD LSRII equipped with FACSDiva

530 Software (BD Bioscience Immunocytometry Systems) and FlowJo software. 
Buehler et al. 24

532 Immunoblotting. Lysates were separated by electrophoresis on precast $12 \%$ Tris-Bis SDS-

533 PAGE gel (Genscript) or 4-20\% precast gels (BioRad). Gels were transferred onto Immobilon-P

534 PVDF membrane (EMD Millipore). Antibodies were incubated in with blocking solution as well.

535 After antibody staining, blots were incubated with fluorescent secondary antibodies and imaged

536 and quantitated using a Li-Cor Odyssey CLx infrared scanner with Image Studio software.

537 Antibodies and sources are defined in Table 2. US22 experiments were developed using

538 chemiluminescence with film and quantified with Image $\mathrm{J}$ software.

RT-qPCR. Cells were infected with $1 \mathrm{MOI}$ of TB40/E $\mathrm{EFF}_{\mathrm{GP}}$ and RNA was isolated using Quick-

DNA/RNA miniprep kit (Zymo Research) from 0-72 hpi. RNA was reverse transcribed into cDNA were calculated by Pfaffl method normalized to H6PD (70).

547 Immunofluorescence. Samples were processed as previously described and stained with

548 antibodies (Table 2; (71)). All images were obtained using a DeltaVision RT inverted

549 Deconvolution microscope. Representative single plane images were adjusted for brightness

550 and contrast.

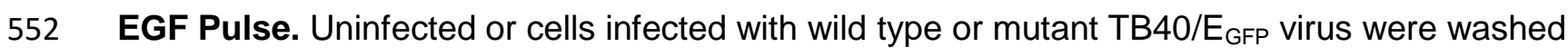
553 two time with PBS and serum starved in serum-free media for $24 \mathrm{~h}$ prior to EGF stimulation.

554 After serum starvation, cells were washed with ice cold PBS and incubated on ice for $30 \mathrm{~min}$. 
Buehler et al. 25

555 Cells were then incubated on ice with serum free media containing 10 nM EGF (Gold

556 Biotechnology) for $30 \mathrm{~min}$, except for no EGF control. Cells were then washed with ice cold

557 PBS. $37^{\circ} \mathrm{C}$ serum free media was added and samples were incubated at $37^{\circ} \mathrm{C}$ for $15 \mathrm{~min}$ to $24 \mathrm{~h}$,

558 depending on experiment. Samples were then collected for immunoblotting or chromatin

559 immunoprecipitation, depending of experiment.

siRNA knockdown. HEK293T cells, seeded into 12-well plates the day before, were cotransfected with the indicated 400ng pGEMT plasmid and 600ng pSiren plasmid per well using Lipofectamine 2000 (Invitrogen). $24 \mathrm{~h}$ later, the cells were serum starved overnight in 0\% FBS inhibitors). The experiment was performed in duplicate.

Measurement of infectious virus. Confluent fibroblasts were infected with either $1 \mathrm{MOI}$ or 0.02 $\mathrm{MOI}$ of either wild type TB40/E $\mathrm{E}_{\mathrm{GFP}}$ or EGR1 mutant virus (TB40/E- $\Delta \mathrm{EGR} 1_{\text {Site } 1}$ and TB40/E$\Delta E G R 1_{\text {site } 2}$ ). For pathway inhibitors, the media was changed 24 hpi with media containing

571 inhibitor and incubated for 8 days. For EGR1 mutant virus studies, media was changed 24 hpi

572 and samples were collected up to $16 \mathrm{dpi}$. Both cells and media were collected and then total

573 virus was quantified by the $\operatorname{TCID}_{50}$ (18). Infectious centers were quantitated in $\mathrm{CD}_{3} 4^{+} \mathrm{HPCs}$, as

574 described previously (71). Frequency of infection centers were calculated using extreme limiting

575 dilution analysis (72). For pathway inhibitors, CD34 ${ }^{+}$HPCs were treated with chemical inhibitors 576 after sorting for $\mathrm{CD}^{+} 4^{+} \mathrm{GFP}^{+}$populations. Inhibitor concentration, targets, and sources are listed 577 in Table 3. 
Buehler et al. 26

Table 3 Chemical Inhibitors

\begin{tabular}{llll} 
Inhibitor & Target & Source & Concentration \\
\hline Binimetinib & MEK1/2 & LC Laboratories & $1 \mu \mathrm{M}$ \\
SCH772984 & ERK1/2 & Selleckchem & $125 \mathrm{nM}$ \\
Fludarabine & STAT1 & Selleckchem & $50 \mu \mathrm{M}$ \\
S3I-201 & STAT3 & Selleckchem & $100 \mu \mathrm{M}$ \\
LY294002 & PI3K & LC Laboratories & $20 \mu \mathrm{M}$ \\
MK-2206 & AKT & Selleckchem & $1.25 \mu \mathrm{M}$ \\
U73122 & PLCY & Selleckchem & $4 \mu \mathrm{M}$
\end{tabular}

Next Generation sequencing analysis. Transcript data was acquired from a previous study HPCs infected with TB40/E $\mathrm{E}_{\text {GFP }}$ at a MOI of 2 at 2 and 6 dpi. Transcripts for EGR1, EGR2, EGR3, and WT1 were normalized to fragments per kilobase per million reads (FPKM) and then normalized to EGR1 levels at 2 dpi. Data from two independent experiments using different donors were combined and graphed together.

ChIP-qPCR. For EGR1 overexpression chromatin immunoprecipitation coupled with qPCR (ChIP-qPCR), MRC-5 fibroblasts were transduced with $1 \mathrm{MOI}$ of EGR1 $1_{3 \times F L A G}$ lentivirus. Transduced cells were then infected with $1 \mathrm{MOI}$ of either wild type TB40/E $\mathrm{E}_{\mathrm{GFP}}$ or TB40/E-

$591 \Delta \mathrm{EGR} 1_{\text {Site } 1}$ for $48 \mathrm{~h}$ and then processed for ChIP. In EGF pulse ChIP-qPCR, fibroblasts were 592 infected with $1 \mathrm{MOI}$ of either wild type TB40/E $\mathrm{E}_{\mathrm{GFP}}$ or TB40/E- $\Delta \mathrm{EGR} 1_{\text {Site } 1}$ and then serum starved at $24 \mathrm{hpi}$. At $48 \mathrm{hpi}$, samples were pulsed with $10 \mathrm{nM}$ EGF for $1 \mathrm{~h}$. All samples were then processed for ChIP-qPCR using SimpleChIP Enzymatic Chromatin IP Kit (Cell Signaling Technologies) as per manufacturer's recommended protocol. ChIP was carried out using rb $\alpha$ EGR1, rb a-Histone H3 (positive control), and Normal rabbit lgG (negative control) and with $4 \mathrm{x}$

$59710^{6}$ infected cells per reaction (Table 1). PCR was performed with primers specific to EGR1 binding site 1 and site 2 in the UL 135 open reading frame and separated on $2 \%$ agarose gel 
with ethidium bromide (Table 2). qPCR was performed with LightCycler SYBR Mix kit (Roche)

600 and Site 1 Forward and Reverse primers. Relative expression was calculated against a $2 \%$

601 input control (Relative expression $\left.=0.02 \times 2^{\left(C T_{2 \% \text { input }}-C T_{C h I P}\right)}\right)$. Samples were then normalized 602 to the relative expression of the WT EGR1 ChIP.

Pathscan Antibody Array. MRC-5 fibroblasts were infected at an MOI of 1 with TB40/E $\mathrm{GFP}$ virus and incubated for 48h. After 48h, samples were washed with PBS twice and either lysed to measure steady state phosphorylation or pulsed with $10 \mathrm{nM}$ of EGF for 30 min and then lysed to

607 measure phosphorylation post stimulation. Phosphorylation levels were measured using the

608 PathScan EGFR Signaling Antibody Array Kit from Cell Signaling as per manufacturer

609 recommended protocol using protein lysates at a concentration of $1 \mathrm{mg} / \mathrm{ml}$. Arrays were

610 analyzed us a LiCOR Odyssey scanner at a resolution of $42 \mu \mathrm{m}$, high quality setting, and exposure intensity of 1 . Phosphorylation levels were normalized to uninfected, no EGF 612 treatment.

614 Statistical Analysis: All statistics were calculated using GraphPad Prism version 7 software.

615 Statistics for experiments in this study were calculated using either Student T-test or analysis of variance (ANOVA) for statistical comparison, which is indicated in the figure legends with $p$ -

617 values for each experiment.

\section{ACKNOWLEDGEMENTS}

620 We acknowledge Dr. Shu Cheng at the University of Arizona for helpful discussion and

621 providing transcript data for this manuscript. We acknowledge Dr. Luwanika Mlera for critical 
Buehler et al. 28

622

623

624

625

626

627

628

629

630

631

632

633

634

635

636

637

638

639

640

641

642

643

644

645

646

647

648

649

650

reading of the manuscript. We acknowledge Mark Curry and the Arizona Cancer Center/Arizona

Research Laboratories Division of Biotechnology Cytometry Core Facility for expertise and

assistance in flow cytometry and Patricia Jansma of the Molecular and Cellular Biology Imaging

Facility for expertise in and assistance in fluorescent imaging. Special thanks to Terry Fox

Laboratory for providing the M2-10B4 and SI/SI cells. We acknowledge Dr. Tom Shenk for the gift of antibodies.

This work was funded by the National Institutes of Health R01 (R01 AI079059) funded to F.G, a National Institutes of Health R01 (R01 Al21640) funded to J.N., a National Institutes of Health P01 (P01 Al127335) funded to F.G. and J.N., and a National Cancer Institute institutional T32 training grant (T32CA009213-36 2014) and American Cancer Society Post-Doctoral Research Fellowship (129842-PF-16-212-01-TBE) funded to J.B.

\section{REFERENCES}

1. Mendelson M, Monard S, Sissons P, Sinclair J. Detection of endogenous human cytomegalovirus in CD34+ bone marrow progenitors. J Gen Virol. 1996;77(12):3099-102.

2. Cheng S, Caviness K, Buehler J, Smithey M, Nikolich-Zugich J, Goodrum F. Transcriptome-wide characterization of human cytomegalovirus in natural infection and experimental latency. Proc Natl Acad Sci U S A. 2017;114(49):E10586-e95.

3. Shnayder M, Nachshon A, Krishna B, Poole E, Boshkov A, Binyamin A, et al. Defining the Transcriptional Landscape during Cytomegalovirus Latency with Single-Cell RNA Sequencing. mBio. 2018;9(2):e00013-18.

4. Boeckh M, Geballe AP. Cytomegalovirus: pathogen, paradigm, and puzzle. The Journal of Clinical Investigation. 2011;121(5):1673-80.

5. Ljungman P, Hakki M, Boeckh M. Cytomegalovirus in Hematopoietic Stem Cell Transplant Recipients. Hematology/oncology clinics of North America. 2011;25(1):151-69.

6. Razonable RR, Humar A, Practice tAIDCo. Cytomegalovirus in Solid Organ Transplantation. American Journal of Transplantation. 2013;13(s4):93-106. 
Buehler et al. 29

7. Ljungman $P$, Engelhard D, Link H, Biron P, Brandt L, Brunet S, et al. Treatment of Interstitial Pneumonitis Due to Cytomegalovirus with Ganciclovir and Intravenous Immune Globulin: Experience of European Bone Marrow Transplant Group. Clinical Infectious Diseases. 1992;14(4):831-5.

8. Kuo CP, Wu CL, Ho HT, Chen CG, Liu SI, Lu YT. Detection of cytomegalovirus reactivation in cancer patients receiving chemotherapy. Clinical Microbiology and Infection. 2008;14(3):221-7. 9. Collins-McMillen D, Kim JH, Nogalski MT, Stevenson EV, Chan GC, Caskey JR, et al. Human Cytomegalovirus Promotes Survival of Infected Monocytes via a Distinct Temporal Regulation of Cellular Bcl-2 Family Proteins. Journal of Virology. 2016;90(5):2356-71.

10. Chan G, Nogalski MT, Bentz GL, Smith MS, Parmater A, Yurochko AD. PI3K-Dependent Upregulation of Mcl-1 by Human Cytomegalovirus Is Mediated by Epidermal Growth Factor Receptor and Inhibits Apoptosis in Short-Lived Monocytes. The Journal of Immunology. 2010;184(6):3213-22. 11. Collins-McMillen D, Stevenson EV, Kim JH, Lee B-J, Cieply SJ, Nogalski MT, et al. Human Cytomegalovirus Utilizes a Nontraditional Signal Transducer and Activator of Transcription 1 Activation Cascade via Signaling through Epidermal Growth Factor Receptor and Integrins To Efficiently Promote the Motility, Differentiation, and Polarization of Infected Monocytes. Journal of Virology. 2017;91(24).

12. Campadelli-Fiume G, Collins-McMillen D, Gianni T, Yurochko AD. Integrins as Herpesvirus Receptors and Mediators of the Host Signalosome. Annual Review of Virology. 2016;3(1):215-36. 13. Collins-McMillen D, Buehler J, Peppenelli M, Goodrum F. Molecular Determinants and the Regulation of Human Cytomegalovirus Latency and Reactivation. Viruses. 2018;10(8):444.

14. Goodrum F. Human Cytomegalovirus Latency: Approaching the Gordian Knot. Annu Rev Virol. 2016;3(1):333-57.

15. Buehler J, Zeltzer S, Reitsma J, Petrucelli A, Umashankar M, Rak M, et al. Opposing Regulation of the EGF Receptor: A Molecular Switch Controlling Cytomegalovirus Latency and Replication. PLoS pathogens. 2016;12(5):e1005655.

16. Kim JH, Collins-McMillen D, Buehler JC, Goodrum FD, Yurochko AD. Human Cytomegalovirus Requires Epidermal Growth Factor Receptor Signaling To Enter and Initiate the Early Steps in the Establishment of Latency in CD34+ Human Progenitor Cells. Journal of Virology. 2017;91(5).

17. Wang X, Huong S-M, Chiu ML, Raab-Traub N, Huang E-S. Epidermal growth factor receptor is a cellular receptor for human cytomegalovirus. Nature. 2003;424(6947):456-61.

18. Umashankar M, Rak M, Bughio F, Zagallo P, Caviness K, Goodrum FD. Antagonistic determinants controlling replicative and latent states of human cytomegalovirus infection. J Virol. 2014;88(11):59876002.

19. Rak MA, Buehler J, Zeltzer S, Reitsma J, Molina B, Terhune S, et al. Human Cytomegalovirus UL135 Interacts with Host Adaptor Proteins To Regulate Epidermal Growth Factor Receptor and Reactivation from Latency. Journal of Virology. 2018;92(20):e00919-18.

20. Rak MAB, Jason; Zeltzer, Sebastian; Reitsema, Justin;Terhune, Scott; and Goodrum, Felicia. Human Cytomegalovirus UL135 Interacts with Host Adaptor Proteins to Regulate Epidermal Growth Factor Receptor and Reactivation from Latency. Journal of Virology. 2018.

21. Min IM, Pietramaggiori G, Kim FS, Passegue E, Stevenson KE, Wagers AJ. The transcription factor EGR1 controls both the proliferation and localization of hematopoietic stem cells. Cell Stem Cell. 2008;2(4):380-91.

22. Sinzger $C$, Hahn G, Digel M, Katona R, Sampaio KL, Messerle M, et al. Cloning and sequencing of a highly productive, endotheliotropic virus strain derived from human cytomegalovirus TB40/E. Journal of General Virology. 2008;89(2):359-68.

23. Fairley JA, Baillie J, Bain M, Sinclair JH. Human cytomegalovirus infection inhibits epidermal growth factor (EGF) signalling by targeting EGF receptors. Journal of General Virology. 2002;83(11):280310. 
Buehler et al. 30

24. Jafferji I, Bain M, King C, Sinclair JH. Inhibition of epidermal growth factor receptor (EGFR) expression by human cytomegalovirus correlates with an increase in the expression and binding of Wilms' Tumour 1 protein to the EGFR promoter. Journal of General Virology. 2009;90(7):1569-74. 25. Peppenelli MA, Arend KC, Cojohari O, Moorman NJ, Chan GC. Human Cytomegalovirus Stimulates the Synthesis of Select Akt-Dependent Antiapoptotic Proteins during Viral Entry To Promote Survival of Infected Monocytes. Journal of Virology. 2016;90(6):3138-47.

26. Chan G, Nogalski MT, Yurochko AD. Activation of EGFR on monocytes is required for human cytomegalovirus entry and mediates cellular motility. Proceedings of the National Academy of Sciences. 2009;106(52):22369-74.

27. Johnson RA, Wang X, Ma X-L, Huong S-M, Huang E-S. Human Cytomegalovirus Up-Regulates the Phosphatidylinositol 3-Kinase (PI3-K) Pathway: Inhibition of PI3-K Activity Inhibits Viral Replication and Virus-Induced Signaling. Journal of Virology. 2001;75(13):6022-32.

28. Reitsma JM, Sato H, Nevels M, Terhune SS, Paulus C. Human Cytomegalovirus IE1 Protein Disrupts Interleukin-6 Signaling by Sequestering STAT3 in the Nucleus. Journal of Virology. 2013;87(19):10763-76.

29. Reitsma JM, Terhune SS. Inhibition of cellular STAT3 synergizes with the cytomegalovirus kinase inhibitor maribavir to disrupt infection. Antiviral Research. 2013;100(2):321-7.

30. Miller $\mathrm{CL}$, Eaves $\mathrm{CJ}$. Long-term culture-initiating cell assays for human and murine cells. Methods Mol Med. 2002;63:123-41.

31. Umashankar M, Goodrum F. Hematopoietic long-term culture (hLTC) for human cytomegalovirus latency and reactivation. Methods Mol Biol. 2014;1119:99-112.

32. Waters KM, Liu T, Quesenberry RD, Willse AR, Bandyopadhyay S, Kathmann LE, et al. Network Analysis of Epidermal Growth Factor Signaling Using Integrated Genomic, Proteomic and Phosphorylation Data. PLOS ONE. 2012;7(3):e34515.

33. Broos S, Soete A, Hooghe B, Moran R, van Roy F, De Bleser P. PhysBinder: improving the prediction of transcription factor binding sites by flexible inclusion of biophysical properties. Nucleic Acids Research. 2013;41(W1):W531-W4.

34. Gineitis D, Treisman R. Differential Usage of Signal Transduction Pathways Defines Two Types of Serum Response Factor Target Gene. Journal of Biological Chemistry. 2001;276(27):24531-9.

35. Cabodi S, Morello V, Masi A, Cicchi R, Broggio C, DiStefano P, et al. Convergence of integrins and EGF receptor signaling via PI3K/Akt/FoxO pathway in early gene Egr-1 expression. Journal of cellular physiology. 2009;218(2):294-303.

36. Chakraborty S, Li L, Puliyappadamba VT, Guo G, Hatanpaa KJ, Mickey B, et al. Constitutive and ligand-induced EGFR signalling triggers distinct and mutually exclusive downstream signalling networks. Nature Communications. 2014;5:5811.

37. Thiel G, Cibelli G. Regulation of life and death by the zinc finger transcription factor Egr-1. Journal of cellular physiology. 2002;193(3):287-92.

38. Grainger L, Cicchini L, Rak M, Petrucelli A, Fitzgerald KD, Semler BL, et al. Stress-Inducible Alternative Translation Initiation of Human Cytomegalovirus Latency Protein pUL138. J Virol. 2010;84(18):9472-86.

39. Umashankar M, Petrucelli A, Cicchini L, Caposio P, Kreklywich CN, Rak M, et al. A novel human cytomegalovirus locus modulates cell type-specific outcomes of infection. PLoS pathogens. 2011;7(12):e1002444.

40. Caviness K, Cicchini L, Rak M, Umashankar M, Goodrum F. Complex Expression of the UL136 Gene of Human Cytomegalovirus Results in Multiple Protein Isoforms with Unique Roles in Replication. Journal of Virology. 2014;88(24):14412-25. 
bioRxiv preprint doi: https://doi.org/10.1101/648543; this version posted May 24, 2019. The copyright holder for this preprint (which was not certified by peer review) is the author/funder, who has granted bioRxiv a license to display the preprint in perpetuity. It is made available under aCC-BY-NC-ND 4.0 International license.

Buehler et al. 31

41. Mikell I, Crawford LB, Hancock M, Mitchell J, Buehler J, Goodrum F, et al. HCMV miR-US22 down -regulation of Egr-1 regulates CD34+ Hematopoietic Progenitor Cell Proliferation and Viral Reactivation. PLoS pathogens. 2019.

42. Englert C, Hou X, Maheswaran S, Bennett P, Ngwu C, Re GG, et al. WT1 suppresses synthesis of the epidermal growth factor receptor and induces apoptosis. The EMBO journal. 1995;14(19):4662-75. 43. Ritchie MF, Yue C, Zhou Y, Houghton PJ, Soboloff J. Wilms tumor suppressor 1 (WT1) and early growth response 1 (EGR1) are regulators of STIM1 expression. The Journal of biological chemistry. 2010;285(14):10591-6.

44. Bentz GL, Yurochko AD. Human CMV infection of endothelial cells induces an angiogenic response through viral binding to EGF receptor and beta1 and beta3 integrins. Proc Natl Acad Sci U S A. 2008;105(14):5531-6.

45. Chan G, Nogalski MT, Stevenson EV, Yurochko AD. Human cytomegalovirus induction of a unique signalsome during viral entry into monocytes mediates distinct functional changes: a strategy for viral dissemination. J Leukoc Biol. 2012;92(4):743-52.

46. Avraham R, Yarden Y. Feedback regulation of EGFR signalling: decision making by early and delayed loops. Nature reviews Molecular cell biology. 2011;12(2):104-17.

47. Lindsey S, Langhans SA. Epidermal growth factor signaling in transformed cells. Int Rev Cell Mol Biol. 2015;314:1-41.

48. Lupberger J, Duong FH, Fofana I, Zona L, Xiao F, Thumann C, et al. Epidermal growth factor receptor signaling impairs the antiviral activity of interferon-alpha. Hepatology. 2013;58(4):1225-35.

49. Yamashita M, Chattopadhyay S, Fensterl V, Saikia P, Wetzel JL, Sen GC. Epidermal growth factor receptor is essential for Toll-like receptor 3 signaling. Science signaling. 2012;5(233):ra50.

50. Ortega J, Li JY, Lee S, Tong D, Gu L, Li GM. Phosphorylation of PCNA by EGFR inhibits mismatch repair and promotes misincorporation during DNA synthesis. Proc Natl Acad Sci U S A. 2015;112(18):5667-72.

51. Camarena V, Kobayashi M, Kim JY, Roehm P, Perez R, Gardner J, et al. Nature and Duration of Growth Factor Signaling through Receptor Tyrosine Kinases Regulates HSV-1 Latency in Neurons. Cell Host \& Microbe. 2010;8(4):320-30.

52. Cliffe Anna R, Arbuckle Jesse H, Vogel Jodi L, Geden Matthew J, Rothbart Scott B, Cusack Corey L, et al. Neuronal Stress Pathway Mediating a Histone Methyl/Phospho Switch Is Required for Herpes Simplex Virus Reactivation. Cell Host \& Microbe. 2015;18(6):649-58.

53. Strunk U, Ramos DG, Saffran HA, Smiley JR. Role of Herpes simplex virus 1 VP11/12 tyrosinebased binding motifs for Src family kinases, p85, Grb2 and Shc in activation of the phosphoinositide 3kinase-Akt pathway. Virology. 2016;498:31-5.

54. Chuluunbaatar U, Roller R, Mohr I. Suppression of Extracellular Signal-Regulated Kinase Activity in Herpes Simplex Virus 1-Infected Cells by the Us3 Protein Kinase. Journal of Virology. 2012;86(15):7771-6.

55. Miller WE, Earp HS, Raab-Traub N. The Epstein-Barr virus latent membrane protein 1 induces expression of the epidermal growth factor receptor. J Virol. 1995;69(7):4390-8.

56. Miller WE, Mosialos G, Kieff E, Raab-Traub N. Epstein-Barr virus LMP1 induction of the epidermal growth factor receptor is mediated through a TRAF signaling pathway distinct from NFkappaB activation. J Virol. 1997;71(1):586-94.

57. Kung C-P, Meckes DG, Raab-Traub N. Epstein-Barr Virus LMP1 Activates EGFR, STAT3, and ERK through Effects on PKCס. Journal of Virology. 2011;85(9):4399-408.

58. Morrison JA, Klingelhutz AJ, Raab-Traub N. Epstein-Barr virus latent membrane protein $2 \mathrm{~A}$ activates beta-catenin signaling in epithelial cells. J Virol. 2003;77(22):12276-84.

59. Swart R, Ruf IK, Sample J, Longnecker R. Latent membrane protein 2A-mediated effects on the phosphatidylinositol 3-Kinase/Akt pathway. J Virol. 2000;74(22):10838-45. 
Buehler et al. 32

60. Iwakiri D, Minamitani T, Samanta M. Epstein-Barr Virus Latent Membrane Protein 2A Contributes to Anoikis Resistance through ERK Activation. Journal of Virology. 2013;87(14):8227-34.

61. Peng L, Wu TT, Tchieu JH, Feng J, Brown HJ, Li X, et al. Inhibition of the phosphatidylinositol 3kinase-Akt pathway enhances gamma-2 herpesvirus lytic replication and facilitates reactivation from latency. The Journal of general virology. 2010;91(Pt 2):463-9.

62. Ford PW, Bryan BA, Dyson OF, Weidner DA, Chintalgattu V, Akula SM. Raf/MEK/ERK signalling triggers reactivation of Kaposi\&apos; s sarcoma-associated herpesvirus latency. Journal of General Virology. 2006;87(5):1139-44.

63. Dyson OF, Traylen CM, Akula SM. Cell Membrane-bound Kaposi's Sarcoma-associated Herpesvirus-encoded Glycoprotein B Promotes Virus Latency by Regulating Expression of Cellular Egr-1. Journal of Biological Chemistry. 2010;285(48):37491-502.

64. Ritchie MF, Yue C, Zhou Y, Houghton PJ, Soboloff J. Wilms Tumor Suppressor 1 (WT1) and Early Growth Response 1 (EGR1) Are Regulators of STIM1 Expression. Journal of Biological Chemistry. 2010;285(14):10591-6.

65. Bedadala GR, Pinnoji RC, Hsia S-CV. Early Growth Response gene 1 (Egr-1) regulates HSV-1 ICP4 and ICP22 gene expression. Cell Research. 2007;17:546.

66. Chang Y, Lee H-H, Chen Y-T, Lu J, Wu S-Y, Chen C-W, et al. Induction of the Early Growth Response 1 Gene by Epstein-Barr Virus Lytic Transactivator Zta. Journal of Virology. 2006;80(15):774855.

67. Wu L-W. Role of Egr-1 in regulation of caveolin-1 gene expression in endothelial cells. Cancer Research. 2006;66(8 Supplement):31-.

68. Warming S, Costantino N, Court DL, Jenkins NA, Copeland NG. Simple and highly efficient BAC recombineering using galK selection. Nucleic Acids Research. 2005;33(4):e36.

69. Petrucelli A, Rak M, Grainger L, Goodrum F. Characterization of a novel Golgi apparatus-localized latency determinant encoded by human cytomegalovirus. J Virol. 2009;83(11):5615-29.

70. Pfaffl MW. A new mathematical model for relative quantification in real-time RT-PCR. Nucleic acids research. 2001;29(9):e45-e.

71. Umashankar M, Rak M, Bughio F, Zagallo P, Caviness K, Goodrum F. Antagonistic Determinants Controlling Replicative and Latent States of Human Cytomegalovirus Infection. Journal of Virology. 2014. 72. Hu Y, Smyth GK. ELDA: Extreme limiting dilution analysis for comparing depleted and enriched populations in stem cell and other assays. Journal of Immunological Methods. 2009;347(1-2):70-8.

\section{Figure Legends}

Figure 1. CMV downregulates EGFR surface and total protein levels as infection

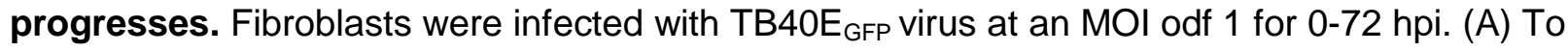
measure EGFR surface levels, infected cells were stained with BV421 conjugated ms $\alpha$-EGFR antibody and analyzed by flow cytometry. Normalized geometric mean fluorescent intensity is shown. (B) Total EGFR levels were measured over a time course by immunoblotting. Blots were 
Buehler et al. 33

831 stained with rb $\alpha$-EGFR, ms $\alpha$-IE1/2 antibody, and ms $\alpha$-Tubulin. Both surface and total EGFR

832 levels were normalized to 0 hpi for statistical analysis. IE proteins serve as a control for infection

833 and tubulin serves as a control for loading. (C) Relative EGFR mRNA levels were measured

834 over a time course using quantitative reverse transcriptase PCR and SYBR green. EGFR

835 transcripts are normalized to H6PD, cellular housekeeping control, at each timepoint. (A-C)

836 Statistical significance was calculated by One-Way ANOVA with Tukey's correction and

837 represented by asterisks ( ${ }^{* * *} p$-values $\left.<0.001\right)$. Graphs represent the means from 3

838 independent replicates with error bars representing SEM. (D) Subcellular localization of EGFR

839 was monitored over a time course of infection. Nuclei, EGFR and IE2 are visualized by staining

840 with DAPI, rb a-EGFR, and ms a-IE2 and confocal deconvolution microscopy.

Figure 2. CMV infection prevents activation of AKT and MEK1/2. (A) Fibroblasts were serum starved for $24 \mathrm{~h}$ and cells were then infected for 0-72 hpi. At each timepoint, infected cells were pulsed with $10 \mathrm{nM}$ of EGFR for 0-30 min, and lysed. Lysates were separated out on SDSPAGE gel, transferred on PVDF membrane, and stained for rb a-EGFR, rb a-pEGFR(Y1068), rb a-pAKT(S472), rb $\alpha-p M E K 1 / 2(S 217 / 221)$, ms $\alpha-I E 1 / 2$ antibody, and ms $\alpha$-Tubulin. (B) The 15

847 min post EGF timepoint for all phosphorylation markers were normalized to uninfected cells and 848 graphed to calculate statistics. Statistical significance was calculated by One-Way ANOVA with

849 Tukey's correction and represented by asterisks ( ${ }^{*} p$-value $<0.05$ and ${ }^{* *} p$-value $\left.<0.01\right)$. Graphs 850 represent the mean of three replicates and error bars represent SEM. 
inhibitors (Binimetinib $1 \mu \mathrm{M}$; SCH772984 125nM), STAT (Fludarabine $50 \mu \mathrm{M}$; S3I-201 $100 \mu \mathrm{M}$ ), PI3K/AKT (LY294002 $20 \mu$ M; MK-2206 $1.25 \mu \mathrm{M})$, PLCY (U73122 $4 \mu \mathrm{M})$. At 8 dpi media and cells were collected and viral titers were determined by $\mathrm{TCID}_{50}$. (B) $\mathrm{CD}_{3} 4^{+} \mathrm{HPC}$ were infected

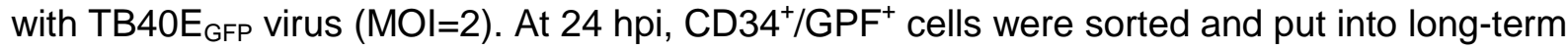
culture with inhibitor list above. After 10 days, parallel populations of either mechanically lysed cells or whole cells were plated onto fibroblasts monolayers in cytokine-rich media and frequency of infectious centers was determined by limited dilution analysis. The mechanically lysed population defines the quantity of virus present prior to reactivation (pre-reactivation). The whole cell population undergoes differentiation due to fibroblasts contact and cytokine stimulation, which promotes viral reactivation (reactivation). The frequency was normalized to the pre-reactivation DMSO control to facilitate comparisons between experiments. Statistical significance was calculated by One-Way ANOVA with Tukey's correction for each condition and represented by asterisks ( ${ }^{*} p$-value $<0.05,{ }^{* *} p$-value $<0.01,{ }^{* * *} p$-value $<0.001$, and ${ }^{* * * *} p$ value $<0.0001)$. For fludarabine infected fibroblasts ANOVA could not measure difference due to absence of quantifiable virus and statistical significance was calculated by student t-test ${ }^{* * * *}$ $\mathrm{p}$-value $<0.0001)$. Data graphed is the mean of 3 replicates with error bars representing SEM.

\section{Figure 4. EGF-stimulation promotes UL138 expression through EGR1 expression. (A)}

Fibroblasts were infected with TB40E $\mathrm{EFF}_{\mathrm{GP}}(\mathrm{MOI}=1)$ and put into serum-free media at $24 \mathrm{hpi}$. Cells were stimulated with 10nM EGF at 48 hpo and cells were harvested between 1 and 24 hours post stimulation. Lysates were separated by SDS-PAGE, transfer onto a member, and blotted with ms $\alpha-I E 1 / 2$, rb $\alpha-U L 135$, rb $\alpha-U L 138$, and ms- $\alpha$ Tubulin. Protein levels from 4 replicates were normalized to no EGF treated control and $1 \mathrm{~h}$ post EGF treatment is graphed. Statistical significance was calculated by student t-test; asterisks ${ }^{* \star *} p$-value $<0.001$. Error bars represent SEM.(B) Graphical representation of putative EGR1 binding sites located within UL135 ORF 
Buehler et al. 35

880

881

882

883

884

885

886

887

888

889

890

891

892

893

894

895

896

897

898

899

900

901

902

903

904

starting at nt-306 and nt-896, in reference to UL135 start codon. P-values were calculated using

PhysBinder prediction software. (C) Fibroblasts were transduced with EGR1 $1_{3 \times F l a g}$ lentivirus and

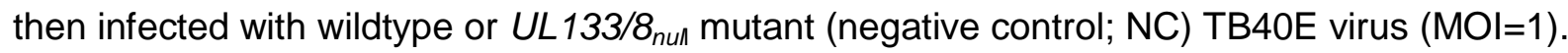
Chromatin was immunoprecipitated (ChIP) with IgG or antibodies specific to EGR1 or histone 3 (H3) and EGR1 binding Site 1 or Site 2 was detected in the precipitates by PCR. As a control, PCR was also performed on $2 \%$ of the ChIP input. Gel is a respresentative experiment from 3 replicates. (D) A model demonstrating how EGFR signaling promotes EGR1 expression by either directing its expression through MEK/ERK signaling or by blocking FOXO1 suppression of EGR1 transcription though PI3K/AKT signaling. (E) Fibroblasts were transduced with either EGR1 $_{3 \times \text { Flag }}$ or Empty vector control and after $24 \mathrm{~h}$ infected with TB40E $\mathrm{GFP}_{\text {. At }} 48 \mathrm{hpi}$, protein lysates were collected, separated by SDS-PAGE and blotted using rb $\alpha-F L A G$, rb $\alpha-U L 138$, and ms a-Tubulin. (F) HEK293T cells were co-transfected with EGR1 $1_{3 \times F l a g}, U L 133 / 8$ encoding plasmid, or empty vector (minus sign). After $48 \mathrm{~h}$, samples were separated by SDS-PAGE and blotted for ms $\alpha-F L A G$, rb $\alpha-U L 138$, and ms $\alpha$-Tubulin. (E-F) UL138 protein levels from either $4(E)$ or $3(F)$ independent experiments were normalized to control and shown in graphs. Statistical significance was calculated by student t-test; asterisks indicate * $p$-value $<0.05$ and ${ }^{\star *} p$-value $<0.01$. Error bars represent SEM. (G) Fibroblasts were infected with $1 \mathrm{MOI}$ of wild type or $\Delta$ miR-US22 TB40E $\mathrm{EFP}_{\mathrm{GF}}$ virus and serum starved overnight before treating with $50 \mathrm{ng} / \mathrm{mL}$ of EGF. Samples were collected at 3 and $4 \mathrm{dpi}$, then separated on a SDS-PAGE gel, and blotted for ms $\alpha$-EGR1, rb $\alpha$-UL138, ms $\alpha$-IE1, and ms $\alpha$-GAPDH. Normalized values for EGR1 and UL138 protein are below each band. Blot is representative of two independent experiments.

\section{Figure 5. EGR1 levels are elevated during latent infection in CD34+ HPCs, but not during} replication in fibroblasts. (A) CD34 ${ }^{+} \mathrm{HPCs}$ were infected with TB40E $\mathrm{E}_{\mathrm{GFP}}(\mathrm{MOI}=2)$. At 2 and 6 dpi, we isolated RNA and prepared mRNA libraries for Illumina sequencing. Relative expression 
905

906

907

908

909

910

911

912

913

914

915

916

917

918

919

920

921

922

923

924

925

926

927

928

929

of EGR1, EGR2, EGR3, and WT1 was calculated by fragments per kilobase per million reads (FPKM) and normalized to EGR1 2 dpi levels. Error bars represent the range of gene expression between two independent donors. (B) Fibroblasts were infected with TB40E $\mathrm{GFP}_{\mathrm{GP}}$ $(\mathrm{MOI}=1)$ and RNA was isolated at 0-72 hpi. EGR1 mRNA was quantified relative to H6PD by RT-qPCR. Results from 3 independent replicates are graphed error bars represent SEM. Statistical significance was calculated by One-Way ANOVA with Tukey's correction and represented by an asterisk ( ${ }^{*} p$-value $\left.<0.05\right)$. (C) Fibroblasts were infected with TB40E $\mathrm{GFP}$ $(\mathrm{MOI}=1)$ and transferred to serum-free media at $24 \mathrm{hpi}$. At $48 \mathrm{hpi}$, samples were pulsed with 10 $\mathrm{nM}$ of EGF for $1 \mathrm{~h}$. Lystates were separated by SDS-PAGE and immunoblotted with rb $\alpha$-EGR1, ms $\alpha$-IE1/2, and ms $\alpha$-tubulin. EGR1 protein levels were normalized to the uninfected sample stimulated with EGF and the mean from 3 independent replicates is graphed. Error bars represent SEM. We calculated statistical significance by two-way ANOVA with Tukey's correction and represented significance by asterisks ( ${ }^{*} p$-value $<0.05$; ${ }^{* * *} p$-value $<0.0001$ ).

\section{Figure 6. Mutation of EGR1 binding sites blocks induction of UL138. (A) HEK293T cells}

were co-transfected with either empty vector or EGR1 $1_{3 \times F L A G}$ and a plasmid contain UL133/8 or a mutant plasmid lacking one EGR1 binding site, $\Delta$ Site 1 or $\Delta$ Site 2 . At $48 \mathrm{~h}$ lystates were separated by SDS-PAGE, and blotted for rb a-Flag, rb $\alpha$-UL138, and ms $\alpha$-tubulin. UL138 protein levels in EGR1 $1_{3 \times F L A G}$ transfections were normalized to control levels to determine UL138 induction. The results from 4 independent replicates are graphed. Statistical significance was calculated by One-Way ANOVA with Bonferroni correction ( ${ }^{*} p$-value $<0.05$ and ** $p$-value $<$ 0.01). (B) HEK293T cells were cotransfected with the UL133/8 vector or the UL133/8 vector where EGR1 sites ( $\Delta$ Site1, $\Delta$ Site 2 ) were disrupted and negative control siRNA, EGR1 siRNA, or miR-US22. Cells were transferred to serum-free media at $24 \mathrm{~h}$. At $48 \mathrm{hpi}$, samples were stimulated with $50 \mathrm{ng} / \mathrm{mL}$ EGF for $1 \mathrm{~h}$ and then lysed, separated by SDS-PAGE, and blotted for 
Buehler et al. 37

930

931

932

933

934

935

936

937

938

939

940

941

942

943

944

945

946

947

948

949

950

951

952

953

rb $\alpha-U L 138$ and ms $\alpha-$ GAPDH. UL138 levels are normalized to negative control. A representative blot of 2 independent experiments is shown.

Figure 7. Disruption of EGR1 site 1 blocks EGR1 binding during infection. (A) Fibroblasts were infected with wild type $\mathrm{TB}_{40 \mathrm{E}_{\mathrm{GFP}}}$ or $\mathrm{EGR} 1$ binding mutant viruses, $\Delta$ Site 1 or $\Delta$ Site 2 (MOI=0.02). Cells and media were collected from 0-16 dpi and virus titers measured by $\mathrm{TCID}_{50}$. The average of 3 independent replicate experiments is shown. (B) Fibroblasts were infected wild type or EGR1 binding mutant viruses. Samples were lysed at $48 \mathrm{hpi}$, separated by SDSPAGE and blotted for ms $\alpha-I E 1 / 2, r b$ - $\alpha$-U135, and rb $\alpha$-UL138, and ms $\alpha$-tubulin. UL138 protein levels were quantified and each mutant was normalized to WT over 3 independent experiments. The average value is graphed with error bars representing SEM and statistical significance is calculated by One-way ANOVA with Bonferroni correction ( ${ }^{*} p$-value $\left.<0.05\right)$. (C) Fibroblasts were transduced with $\mathrm{EGR}_{3 \times \mathrm{Flag}}$ lentivirus for $24 \mathrm{~h}$ and then infected with wild type $\mathrm{TB}_{40 \mathrm{E}_{\mathrm{GFP}} \text { or }}$ TB40E- $\triangle \mathrm{EGR} 1_{\text {Site } 1}$ mutant virus $(\mathrm{MOI}=1)$. After $48 \mathrm{~h}$, samples were immunoprecipitated for either IgG or EGR1 and processed for ChIP-qPCR using SimpleChIP Enzymatic Chromatin IP

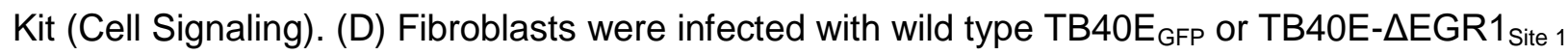
mutant virus $(\mathrm{MOI}=1)$ and transferred to serum-free media at $24 \mathrm{hpi}$. At $48 \mathrm{hpi}$, samples were pulsed with $10 \mathrm{nM}$ EGF for $1 \mathrm{~h}$ and processed for ChIP-qPCR as was done in E. For both $\mathrm{E}$ and $\mathrm{F}$, the presence of EGR1 Site 1 sequence was calculated relative to a $2 \%$ input control $\left(\right.$ Relative expression $\left.=0.02 \times 2^{\left(C T_{2 \% \text { input }}-C T_{C h I P}\right)}\right)$ and normalized to wild type levels.

Figure 8. Inhibition of EGR1 binding to site 1 disrupts CMV latency. (A) CD34 ${ }^{+}$HPCs were infected with either wildtype TB40E $\mathrm{GFP}_{\mathrm{GF}}$ or TB40E- $\triangle \mathrm{EGR} 1_{\text {Site } 1}$ mutant virus $(\mathrm{MOI}=2)$. At $24 \mathrm{hpi}$, $\mathrm{CD}^{+} / \mathrm{GPF}^{+}$cells were sorted and seeded into long-term culture. After 10 days in culture, 
954

955

956

957

958

959

960

961

962

963

964

965

966

967

968

969

970

971

972

973

974

975

976

977

parallel populations of either mechanically lysed cells or whole cells were plated onto fibroblast monolayers in cytokine-rich media. 14 days later, GFP+ wells were scored and frequency of infectious centers was determined by extreme limited dilution analysis (reactivation). The mechanically lysed population defines the quantity of virus present prior to reactivation (prereactivation). The frequency was normalized to wild type pre-reactivation and the average of three independent experiments is shown. Statistical significance was calculated by one-way ANOVA with Tukey's correction and represented by asterisks ( ${ }^{*} p$-value $\left.<0.05\right)$.

\section{Figure 9. UL138 expression is regulated by a positive feedback mechanisms through} EGFR signaling. Our data demonstrates that EGFR signaling promotes UL138 expression through an upstream EGR1 binding site within a promoter in the UL133/8 locus that remains to be mapped. The EGFR signaling pathway drives the establishment of latency, at least in part, by stimulating UL138 expression, which can function to sustain EGFR signaling. While we have previously shown that UL135 targets EGFR for turnover, miR-US22 provides an additional point of control for reactivation in targeting EGR1.

\section{SUPPORTING INFORMATION}

Figure S1. Phosphorylation screen of EGFR signaling pathways during CMV infection.

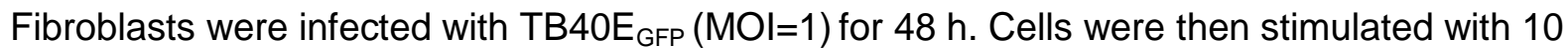
nM EGF for 30 min and lysed for PathScan EGFR Signaling Antibody Array Kit (Cell Signaling) analysis. Parallel unstimulated samples were lysed for comparison. Phosphorylation levels for EGFR, MEK/ERK, AKT, and STAT3 markers were normalized to uninfected, no EGF levels and graphed. Data represents two independent screens each containing two internal technical replicates. Error bars represent the range of the means from each experiment. 
Buehler et al. 39

979 Figure S2. Confirmation of chemical inhibition. Fibroblasts were treated with (A) DMSO, (B)

980 MEK/ERK inhibitors (Binimetinib; SCH772984), (C) STAT (Fludarabine; S3I-201), (D) PI3K/AKT

981 (LY294002; MK-2206), (E) PLCy (U73122) and lysates were isolated from 1-5 days. Samples

982 were separated by SDS-PAGE and blotted for rb $\alpha$-pAKT(S472), rb a-pERK1/2(T202/204), rb a-

983 pSTAT3(Y705), ms $\alpha$-IE1/2 antibody, and ms $\alpha$-Tubulin. Inhibitor protein phosphorylation levels

984 were normalized to DMSO controls.

986 Figure S3. Diagram of EGR1 binding site mutation. UL135 nucleotide sequence was altered

987 in both a pGEM-T virus plasmid and TB40E $\mathrm{EFP}_{\mathrm{GF}}$ bacteria artificial chromosome backbone to

988 disrupt EGR1 binding site 1 (A) and EGR1 binding site 2 (B). Mutations were engineered into

989 the wobble codon in order to alter the nucleotide sequence but not the amino acid sequence of

990 UL135. Binding sequence for each site is underlined and nucleotides mutated are indicated in

991 grey boxes and bolded text. 
bioRxiv preprint doi: https://doi.org/10.1101/648543; this version posted May 24, 2019. The copyright holder for this preprint (which was not certified by peer review) is the author/funder, who has granted bioRxiv a license to display the preprint in perpetuity. It is made available under aCC-BY-NC-ND 4.0 International license.

Buehler et al. 40

Figure 1

A

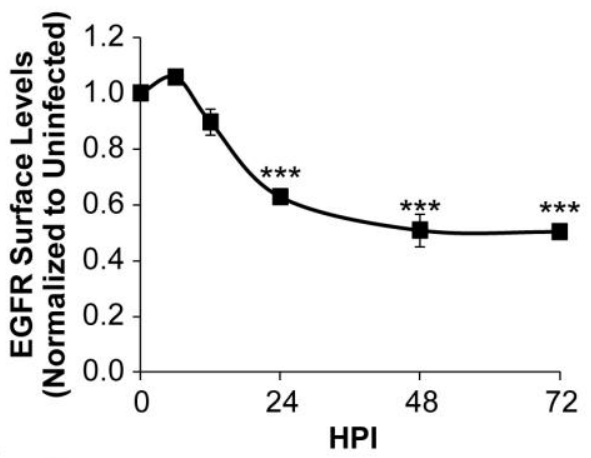

B
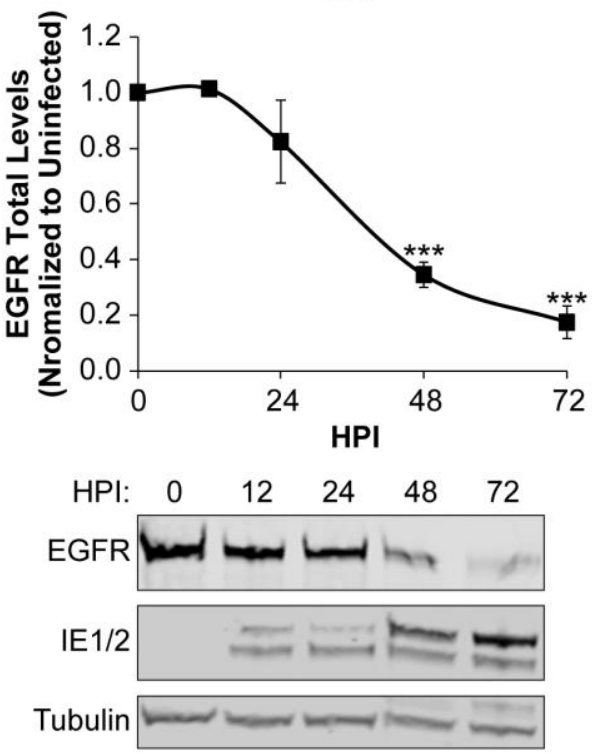

C

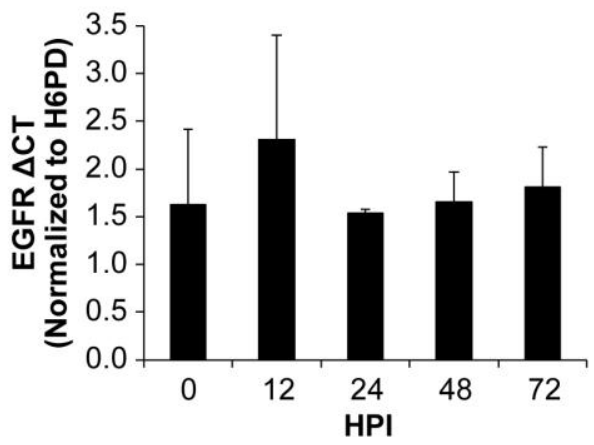

D

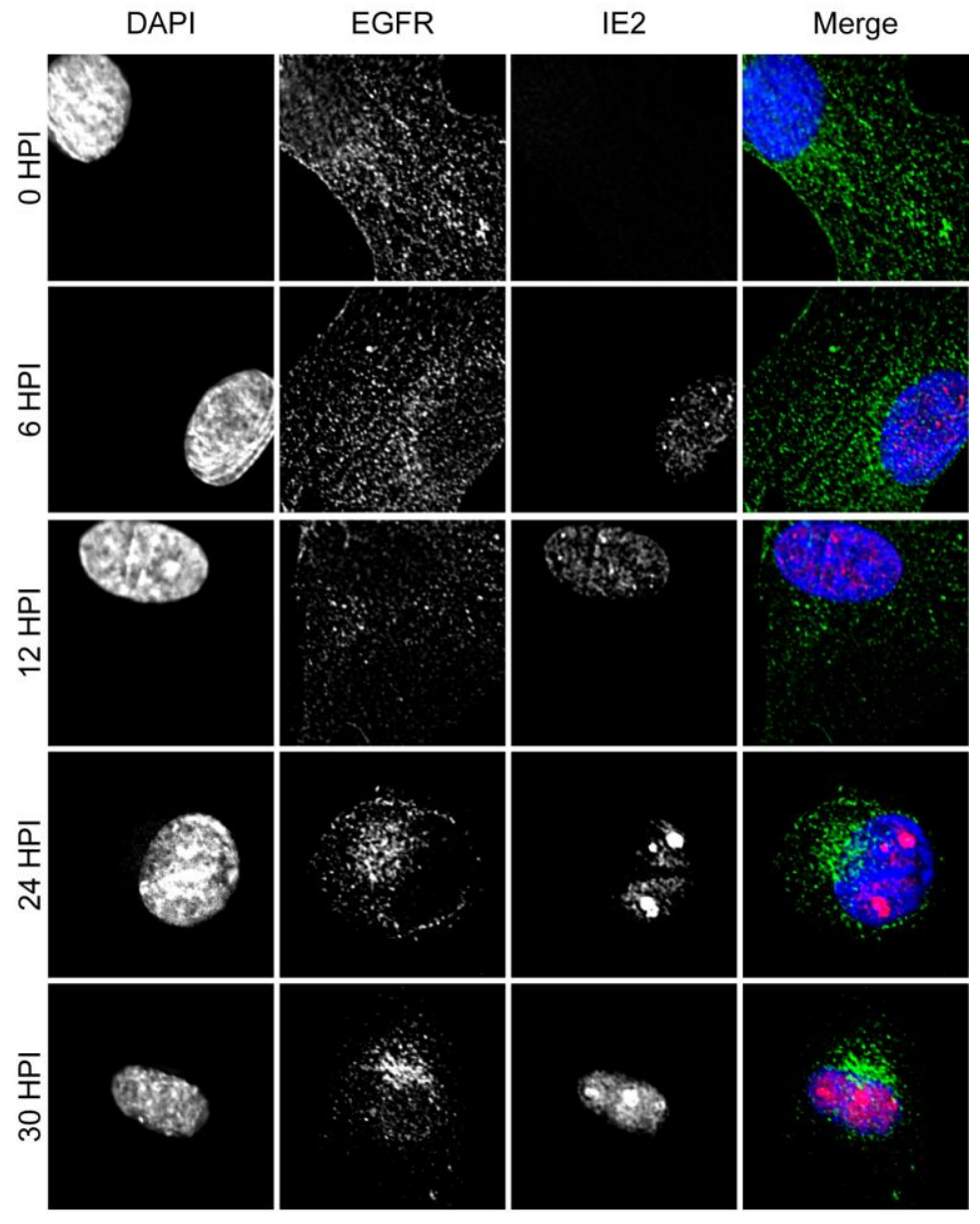


bioRxiv preprint doi: https://doi.org/10.1101/648543; this version posted May 24, 2019. The copyright holder for this preprint (which was not certified by peer review) is the author/funder, who has granted bioRxiv a license to display the preprint in perpetuity. It is made available under aCC-BY-NC-ND 4.0 International license.

Buehler et al. 41

Figure 2

A

TB40E-5 MOI 1

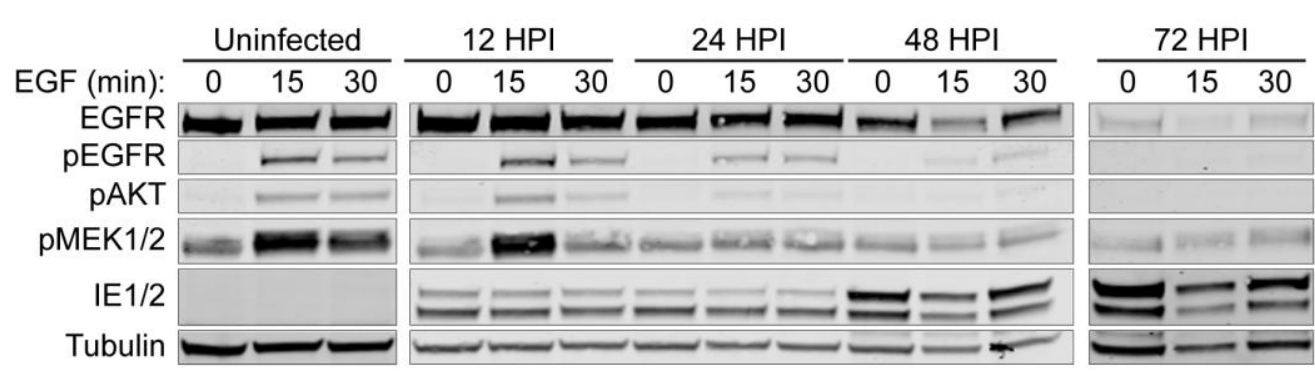

B

$$
\text { PEGFR (Y1068) }
$$
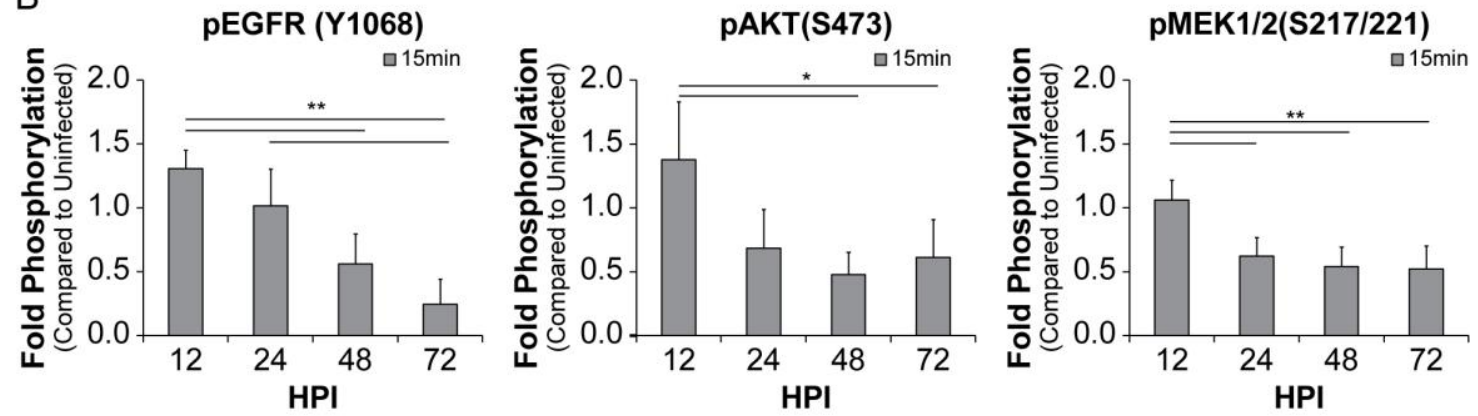
Buehler et al. 42

Figure 3
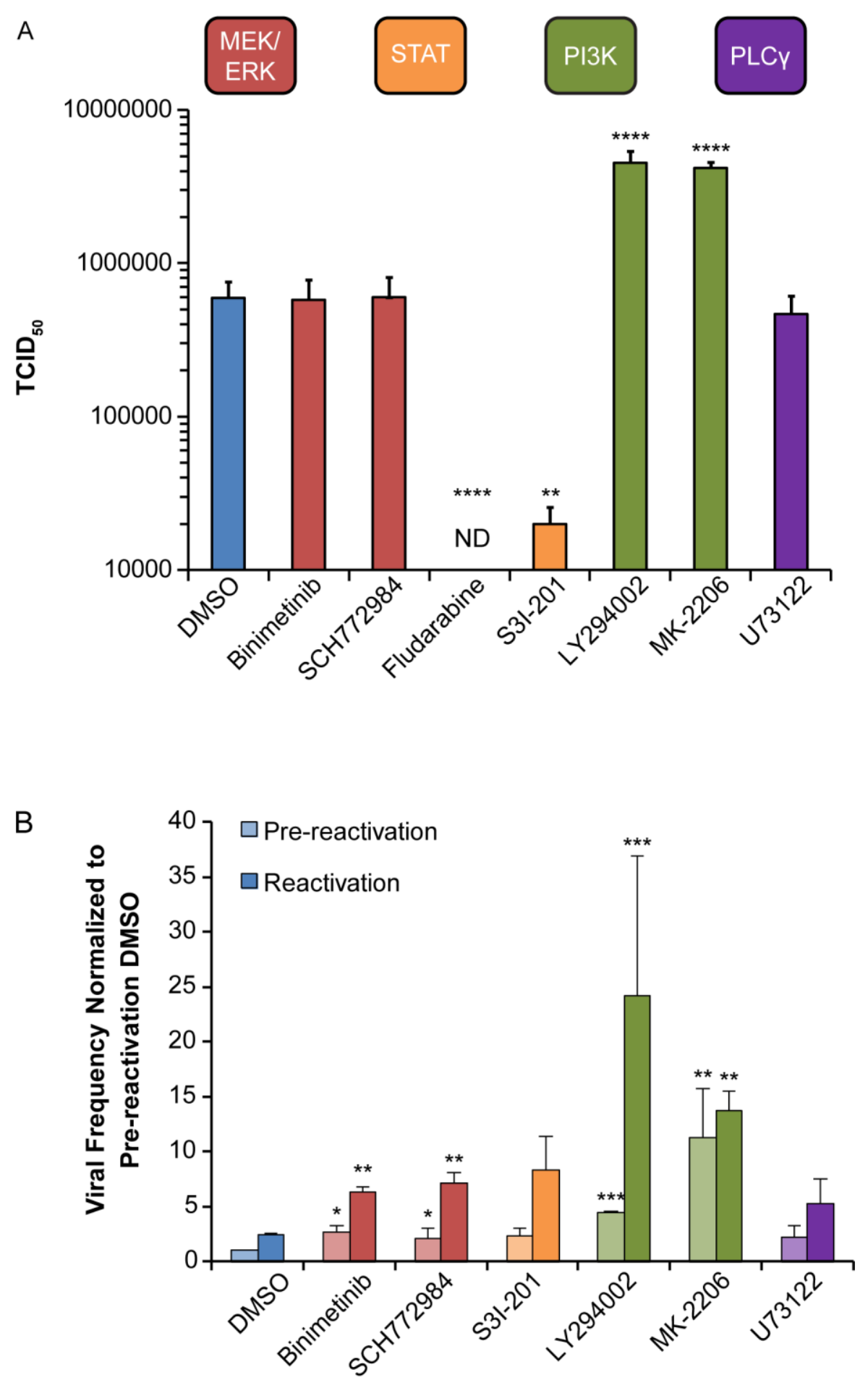
bioRxiv preprint doi: https://doi.org/101101/648543; this version posted May 24,2019 . The copyright holder for this preprint (which was not certified by peer review) is the author/funder, who has granted bioRxiv a license to display the preprint in perpetuity. It is made available under aCC-BY-NC-ND 4.0 International license.

Buehler et al. 43

Figure 4

A

(10 nM EGF)

IE2

IE1

UL135

UL138

Tubulin

B

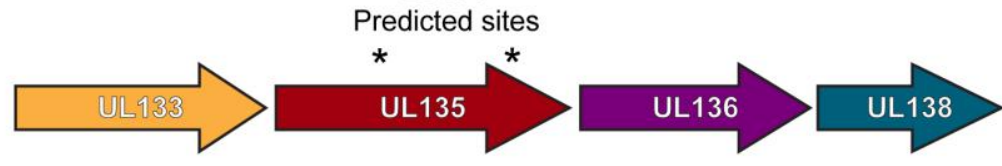

TB40E-5

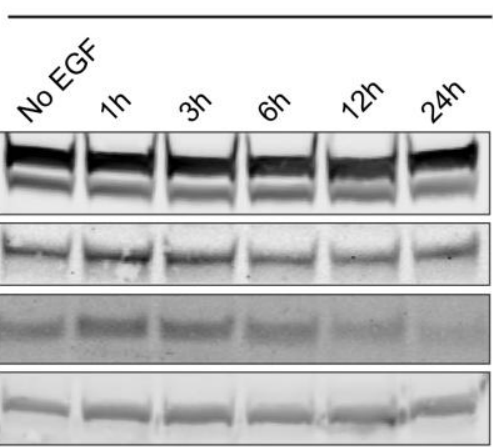

EGR-1

edicted sites

UL135

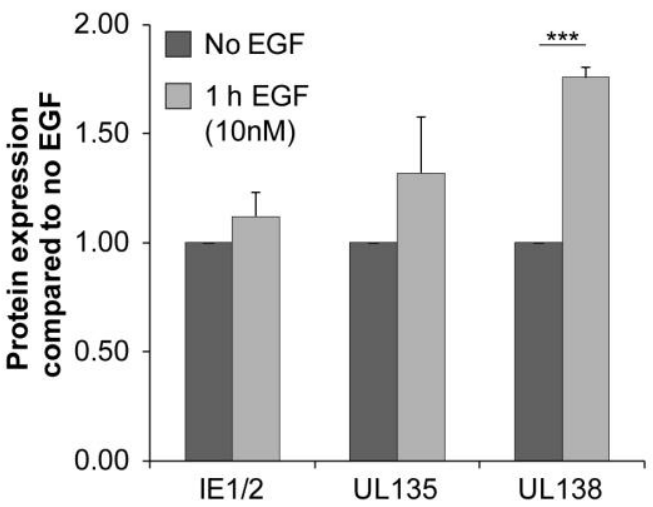

D

Site 1 nt300-CCACCCACCCGCCGACGCCGCAGGTG-nt325 PValue: $7.83655 \times 10^{-17}$

Site 2 nt885-TTCCGAGTTAGCCCCGCCTCCTCGAT-nt910 PValue: $6.22547 \times 10^{-16}$

C

\begin{tabular}{|c|c|c|c|c|c|c|c|c|}
\hline & \multicolumn{4}{|c|}{ ChIP } & \multicolumn{4}{|c|}{ Input } \\
\hline Virus & WT & NC & WT & WT & WT & NC & WT & WT \\
\hline Antibody & $\lg G$ & EGR1 & EGR1 & $\mathrm{H} 3$ & $\lg G$ & EGR1 & EGR1 & $\mathrm{H} 3$ \\
\hline
\end{tabular}

Site 1 Primer

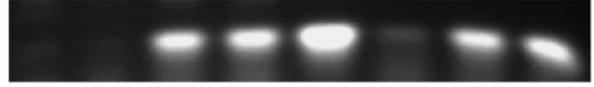

Site 2 Primer
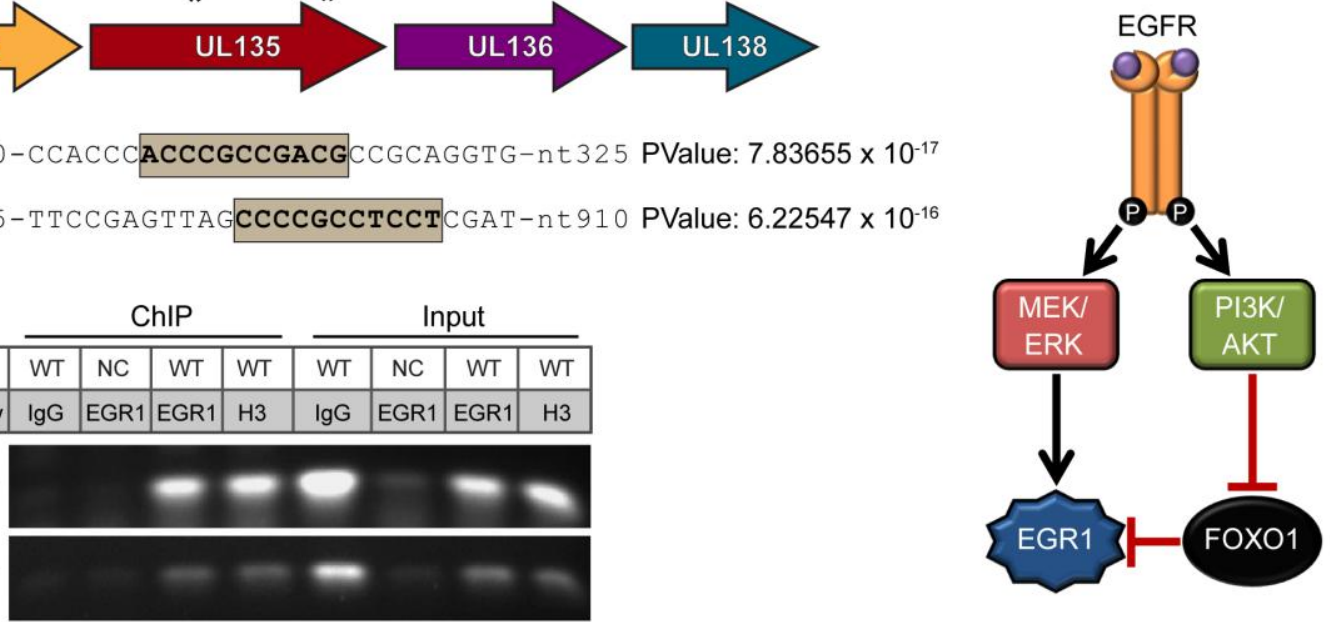
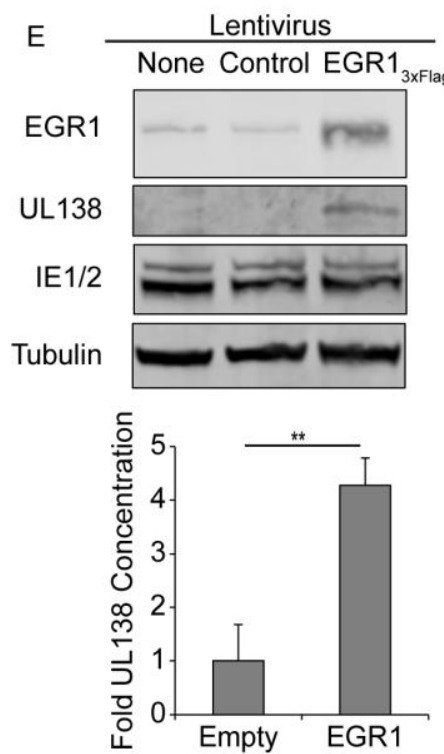

F

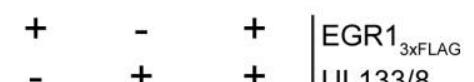

$+\quad+\quad+\quad$ UL133/8
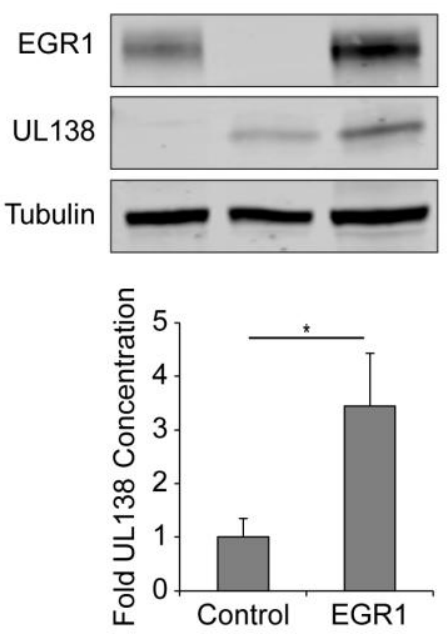

G

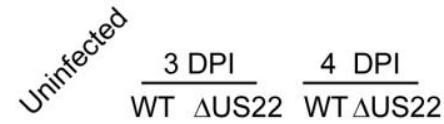

EGR1

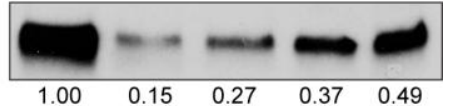

UL138

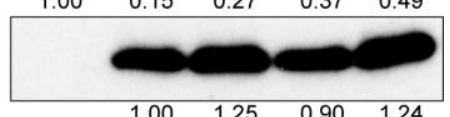

IE1

GAPDH 
bioRxiv preprint doi: https://doi.org/10.1101/648543; this version posted May 24, 2019. The copyright holder for this preprint (which was not certified by peer review) is the author/funder, who has granted bioRxiv a license to display the preprint in perpetuity. It is made available under aCC-BY-NC-ND 4.0 International license.

Buehler et al. 44

Figure 5

A

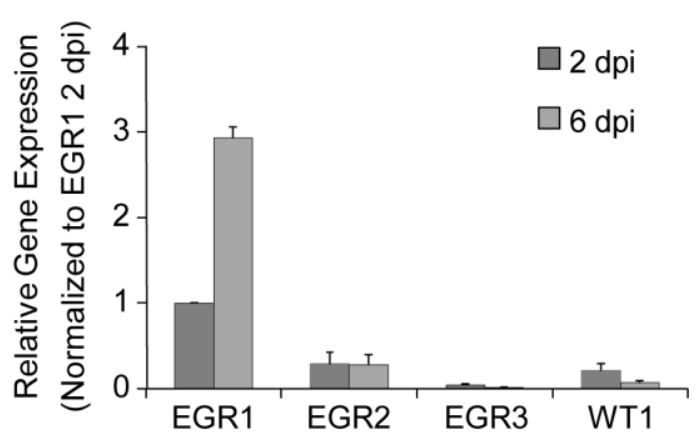

B

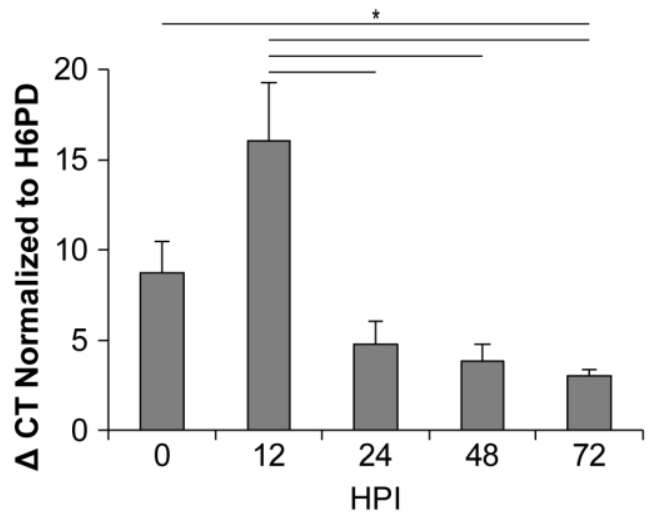

C
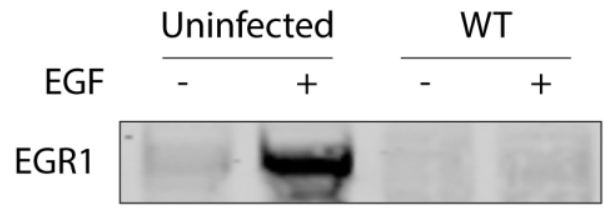

IE1/2

Tubulin
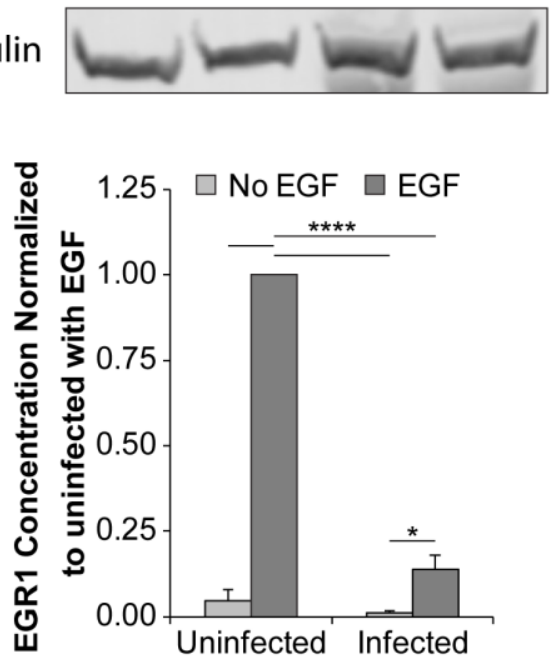
bioRxiv preprint doi: https://doi.org/10.1101/648543; this version posted May 24, 2019. The copyright holder for this preprint (which was not certified by peer review) is the author/funder, who has granted bioRxiv a license to display the preprint in perpetuity. It is made available under aCC-BY-NC-ND 4.0 International license.

Buehler et al. 45

\section{Figure 6}
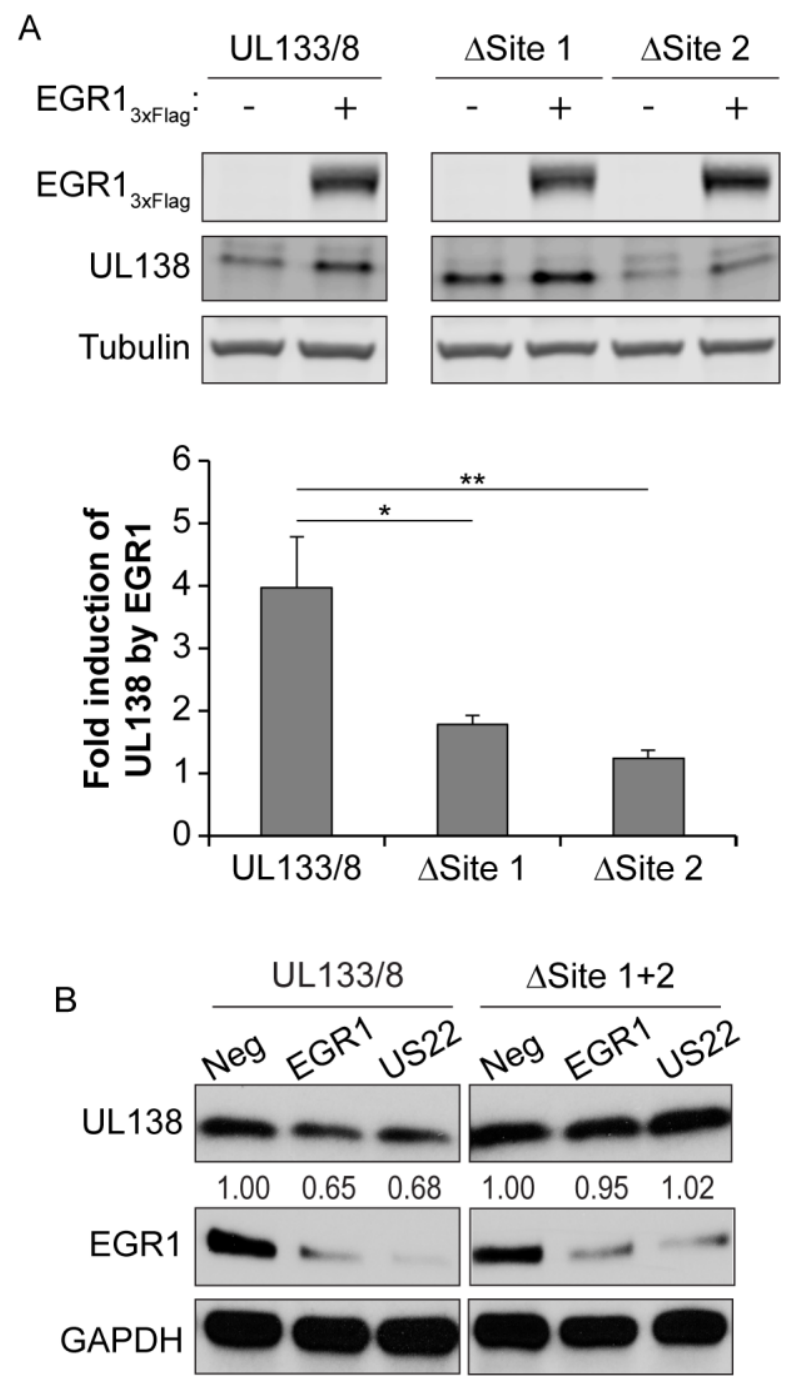
Figure 7
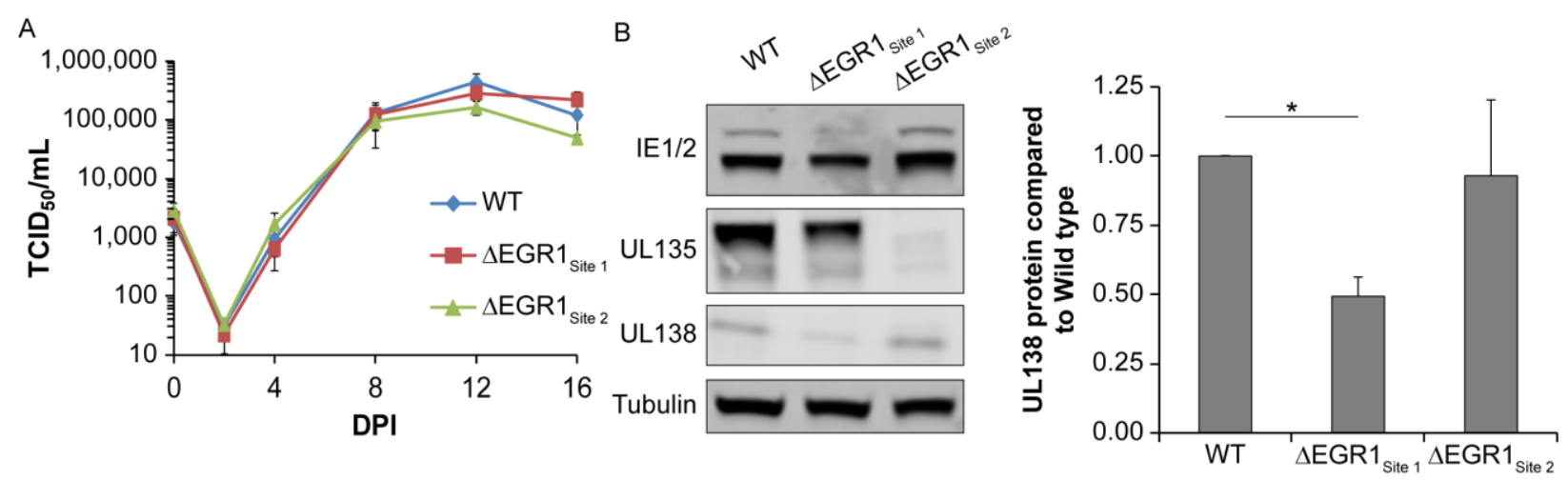

C

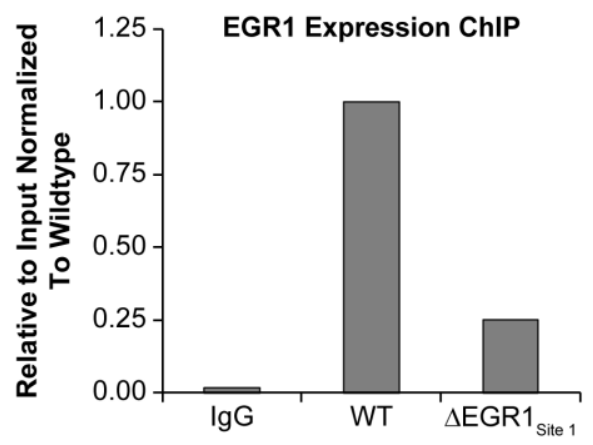

D

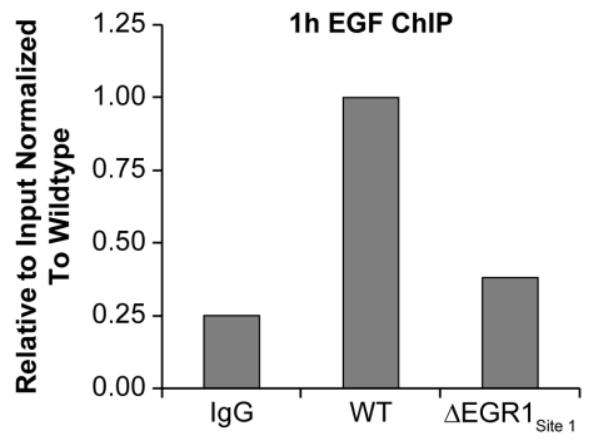


bioRxiv preprint doi: https://doi.org/10.1101/648543; this version posted May 24, 2019. The copyright holder for this preprint (which was not certified by peer review) is the author/funder, who has granted bioRxiv a license to display the preprint in perpetuity. It is made available under aCC-BY-NC-ND 4.0 International license.

Buehler et al. 47

\section{Figure 8}

1005

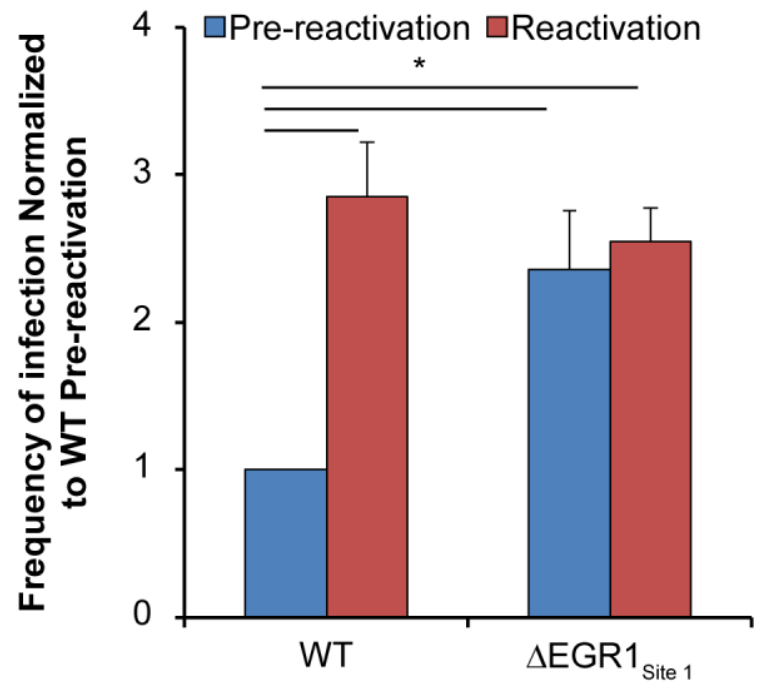


bioRxiv preprint doi: https://doi.org/10.1101/648543; this version posted May 24, 2019. The copyright holder for this preprint (which was not certified by peer review) is the author/funder, who has granted bioRxiv a license to display the preprint in perpetuity. It is made available under aCC-BY-NC-ND 4.0 International license.

Buehler et al. 48

\section{Figure 9}

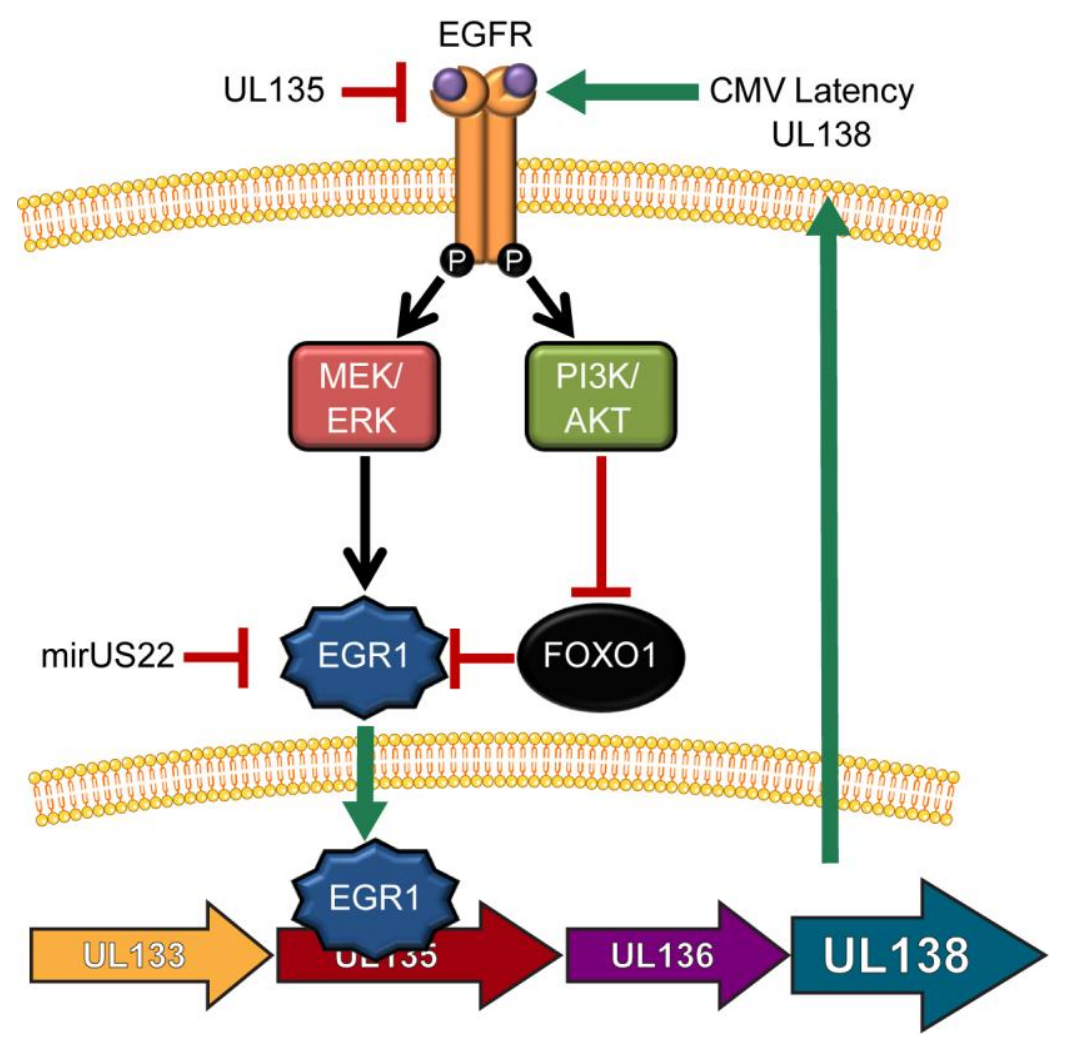


Buehler et al. 49

Figure S1

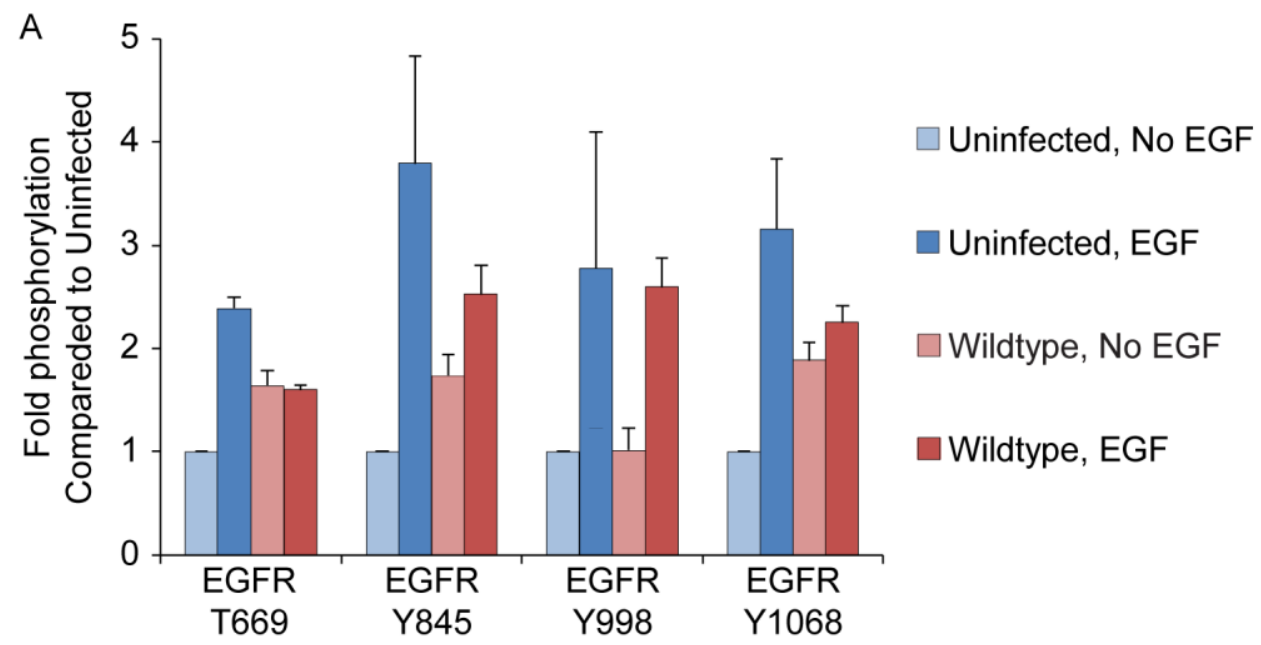

B

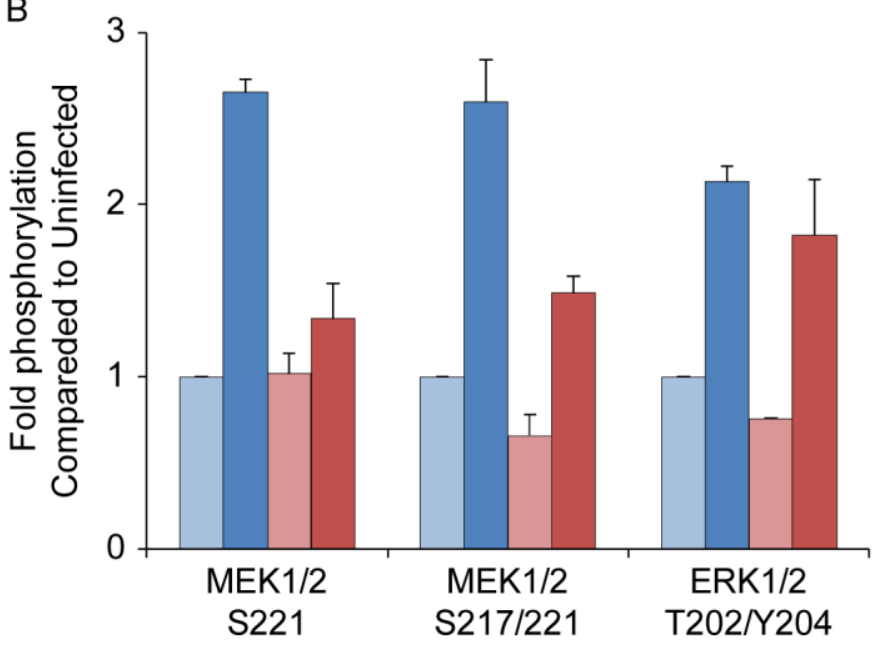

$\square$ Uninfected, No EGF

Uninfected, EGF

$\square$ Wildtype, No EGF

$\square$ Wildtype, EGF
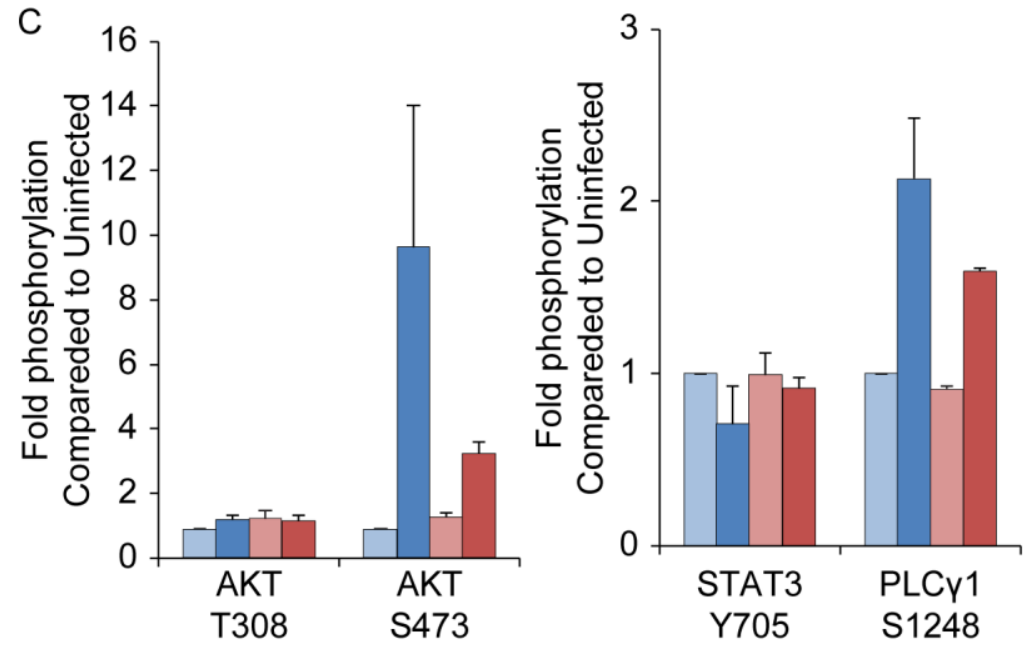

$\square$ Uninfected, No EGF

Uninfected, EGF

$\square$ Wildtype, No EGF

Wildtype, EGF 
Buehler et al. 50

Figure S2

A. No drug

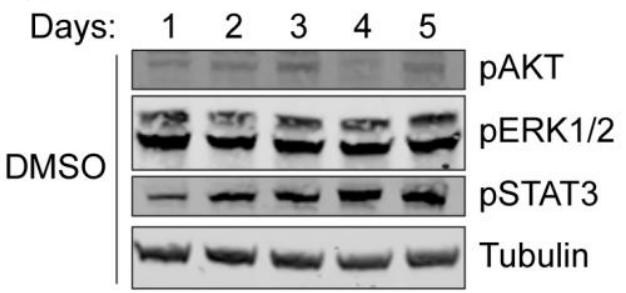

B. MEK/ERK inhibitors

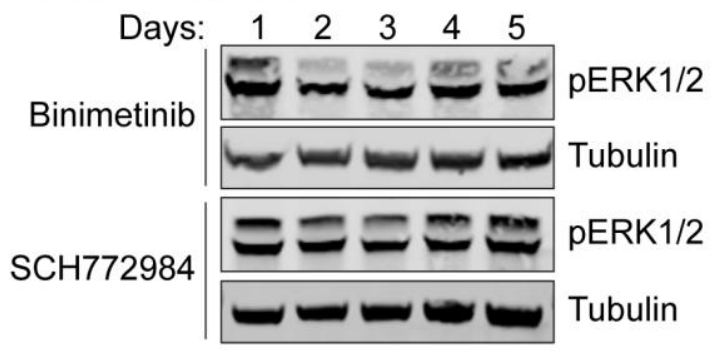

C. PI3K/AKT inhibitors

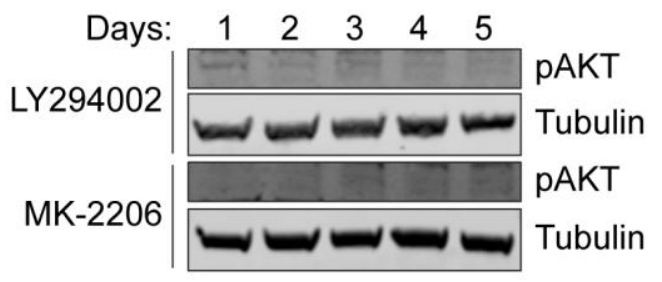

D. STAT inhibitors

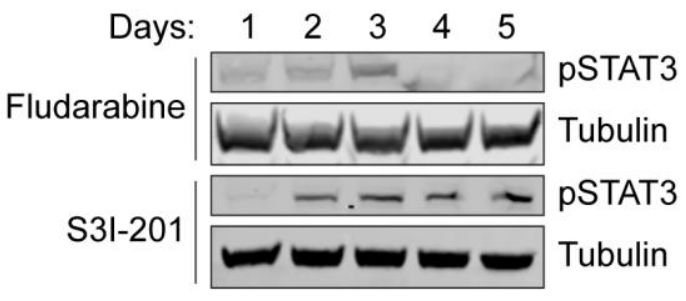

E. PLC $\gamma$ inhibtor

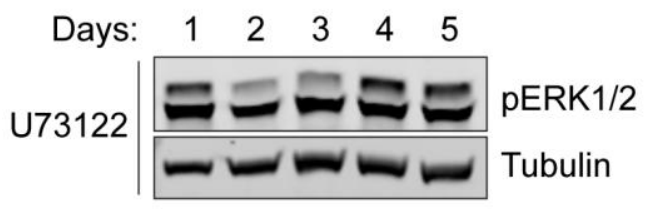

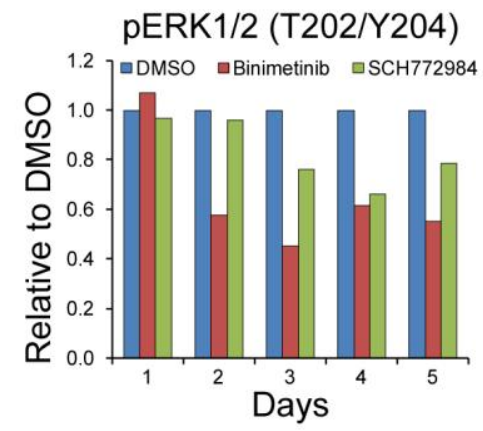
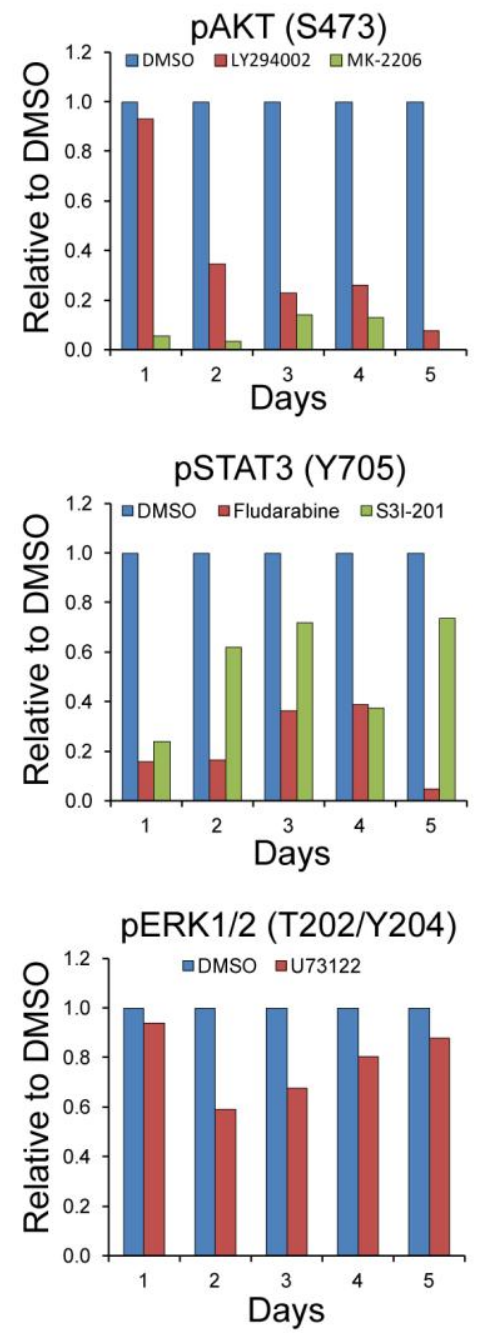
bioRxiv preprint doi: https://doi.org/10.1101/648543; this version posted May 24, 2019. The copyright holder for this preprint (which was not certified by peer review) is the author/funder, who has granted bioRxiv a license to display the preprint in perpetuity. It is made available under aCC-BY-NC-ND 4.0 International license.

Buehler et al. 51

\section{Figure S3}

A

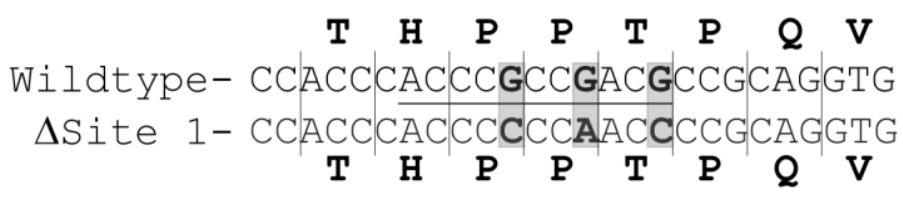

B

$$
\begin{aligned}
& \begin{array}{lllllllll}
\mathbf{S} & \mathbf{E} & \mathbf{L} & \mathbf{A} & \mathbf{P} & \mathbf{P} & \mathbf{P} & \mathbf{R}
\end{array} \\
& \text { Wildtype- TTCCGAGTTAGCCCCGCCTCCTCGAT } \\
& \text { Site 2- TTCCGAGTTAGCCCCCCCACCCCGAT } \\
& \begin{array}{llllllll}
\mathbf{S} & \mathbf{E} & \mathbf{L} & \mathbf{A} & \mathbf{P} & \mathbf{P} & \mathbf{P} & \mathbf{R}
\end{array}
\end{aligned}
$$

